\title{
Lost in Translation? On the Need for Convergence in Animal and Human Studies on the Role of Dopamine in Diet-Induced Obesity
}

\author{
Lieneke K. Janssen ${ }^{1,2} \cdot$ Nadine Herzog $^{1,2} \cdot$ Maria Waltmann ${ }^{1,2} \cdot$ Nora Breuer $^{1,2} \cdot$ Kathleen Wiencke $^{1,2}$. \\ Franziska Rausch $^{1,2,3}$ • Hendrik Hartmann ${ }^{2,3}$ - Maria Poessel ${ }^{2}$. Annette Horstmann ${ }^{1,2,3,4}$
}

Published online: 8 August 2019

(C) The Author(s) 2019, corrected publication 2019

\begin{abstract}
Purpose of Review Animal and human studies suggest that diet-induced obesity and plasticity in the central dopaminergic system are linked. However, it is unclear whether observed changes depend on diet or obesity, and whether they are specific to brain regions and cognitive functions. Here, we focus on neural and cognitive changes in frontostriatal circuits.

Recent Findings Both diet and obesity affect dopaminergic transmission. However, site and direction of effects are inconsistent across species and studies. Non-specific changes are observed spanning all frontostriatal loops, from sensory input to motivated behaviour. Given the impact of peripheral signals on central dopaminergic signalling and the interaction between the frontostriatal loops, modulation of dopamine likely propagates through all loops and, thus, affects behaviour on various levels of complexity.

Summary To improve convergence between animal and human studies on diet-induced obesity, animal studies should include sophisticated cognitive measures and diets resembling human obesogenic diets, and human studies should adopt diet interventions and longitudinal designs.
\end{abstract}

Keywords Obesity $\cdot$ Dopamine $\cdot$ Diet $\cdot$ Frontostriatal loops

\section{Introduction}

Obesity has been associated with prominent changes in dopamine transmission [1-3] and cognitive domains that are crucial for adaptive behaviour, such as motivation, decision-making, reinforcement learning and working memory [4-9]. Importantly, food-related but also general non-food-related cognitive differences have been

This article is part of the Topical Collection on Food Addiction

Annette Horstmann

horstmann@cbs.mpg.de

1 Integrated Research and Treatment Center Adiposity Diseases, Leipzig University Medical Center, Leipzig, Germany

2 Department of Neurology, Max Planck Institute for Human Cognitive and Brain Sciences, Leipzig, Germany

3 Collaborative Research Centre 1052 “Obesity Mechanisms”, Leipzig University Medical Center, Leipzig, Germany

4 Department of Psychology and Logopedics, Faculty of Medicine, University of Helsinki, Helsinki, Finland recently highlighted in obesity [10-16]. However, animal studies contributed to the understanding that obesogenic diet, rather than adiposity itself, actually causes observed differences in dopamine transmission $[17,18 \bullet \bullet, 19-21]$.

Excellent obesity-related reviews have focused on either DA transmission [22], or cognition with little or no emphasis on the relation with dopamine $[7,11,15]$. Others have argued for dopamine-mediated cognitive changes in obesity $[1-3,8$, 9, 23-27] paralleling findings from addiction research, with controversial opinions towards the existence of food addiction [22, 23, 28-31]. Here, we argue for a more detailed assessment on the relationship between dopamine and the variety of possibly dopamine-mediated cognitive changes in obesity.

Some reviews suggested a major role of reward function in obesity, which resonates well with abundant evidence for striatal dopamine alterations in both animals and humans. Others have argued for a deficit that is predominantly mediated by the prefrontal cortex (PFC) (e.g. [10, 32]), which is not well investigated regarding a direct link to the dopaminergic system yet. Both perspectives might mirror different angles of the same changes as dense anatomical connections exist 
between frontal and striatal regions. These connections are organised in functionally relevant frontostriatal loops that are strongly modulated by dopamine. This makes it important to examine the cognitive literature in obesity in the light of these frontostriatal loops.

Here, we will address the following open questions: First, do findings from animal and human studies on dopamine changes converge, given the different methodologies available to study the dopaminergic system in these species? Second, does a comprehensive picture emerge regarding major obesity-related cognitive differences and their possible association with frontostriatal loops? Third, can these differences be regarded as global, i.e. affecting several cognitive domains, or are they specific to, e.g. the food context? Fourth, to what extent are diet-induced dopamine differences responsible for the observed differences in cognitive domains? And fifth, what are candidate mechanistic links between diet and central dopamine?

In this review, we will summarise recent findings of obesity and diet-related differences in dopamine transmission, in particular in the striatum, from human and animal studies. We will then describe the different frontostriatal loops, followed by an evaluation of obesity-related differences in the sensory input to this circuit. Finally, we will discuss the neurocognitive profile of obesity within the theoretical framework of frontostriatal loops. We will point out major gaps in the literature, as well as challenges that need to be overcome in order to get at the heart of the role of dopamine in diet-induced obesity.

\section{Obesity and Diet-Related Dopamine Differences}

In humans, structural changes in the dopamine system can be imaged most directly with positron emission tomography (PET) using radioactively labeled ligands that bind to a specific substrate. Such studies have revealed obesity-related differences, in particular related to D2receptor (D2R) (Appendix Table 1). D2R binding has been found to correlate positively to BMI in normalweight to obese individuals in several studies $[49,52$, 94], but not in others $[57,59,71]$. In the latter study, dopamine release did correlate positively with BMI in putamen and substantia nigra [59]. Another PET study revealed a positive relationship with BMI in the dorsal and lateral striatum, whereas a negative relationship was observed in the ventral striatum [53]. These, together with other inconsistent results concerning D2R binding in human obesity, have been proposed to reflect a quadratic relationship between severity of obesity and striatal D2R availability, or rather a U-shaped relationship with dopamine tone [2]. The idea of lower tone in overweight to mildly obese individuals is supported by a recent $[18 \mathrm{~F}]$ DOPA PET study [62•]. However, striatal dopamine transporter (DAT) binding as measured with single-photon emission computed tomography (SPECT) did not relate to BMI in a sample of normal-weight to severely obese participants [95], nor to self-reported ad libitum food intake in normal-weight participants [90•]. Importantly, due to the cross-sectional design of most human studies, it is debated whether or not the observed differences in dopamine transmission in humans are cause or consequence of obesity.

Rodent models allow for the investigation of more causal links between obesity and dopamine transmission and have begun to disentangle the effects of an obesogenic diet from adiposity. Short-term and chronic high fat diets (HFDs) as well as diet-induced obesity were shown to reduce D2RmRNA and protein expression levels ([96-99], but see [100]) (Table 2). An elegant study suggests that diet-induced obesity may be the cause rather than the result of reduced D2R availability $[18 \bullet \cdot]$. The authors found decreased striatal D2R binding after a chronic HFD, despite unchanged D2R-mRNA or protein levels, which could be explained by receptor internalisation. D2R binding also did not predict weight gain, nor did deletion of D2Rs in striatal neurons increase risk for obesity. Overexpression of striatal D2Rs in development has been shown to causally relate to diet-induced obesity through its effect on energy expenditure and thermogenesis [103]. Effects of sugar on the dopamine system have also been observed, although the findings diverge. One study showed increased D2R-mRNA expression and decreased D2R-protein levels in the nucleus accumbens [104], whereas others found the opposite for the striatum as a whole [100]. This may be due to the specific striatal regions under study or the diet composition (for more details on diet composition and duration, see Appendix Table 2). Moreover, chronic HFD may also lead to reduced D1R-mRNA in the rat striatum $([97,101]$, but see $[18 \bullet \bullet, 105])$ depending on diet composition [106]. One study showed reduced D1R signalling when a diet high in saturated, but not monounsaturated fats (palm oil vs. olive oil), was administered [101]. Finally, diet-related changes in dopamine synthesis [108], release [59, 102, 105] and uptake (DAT) $[98,99]$ have been observed.

In sum, excessive weight and chronic exposure to an obesogenic diet has been associated with changes in striatal dopamine transmission in humans and rodents, in particular related to D2Rs. The wide variety of observed diet-induced dopamine changes described above suggests a complex interplay between obesogenic diet and the different parts of the dopamine pathway. Future research is required to get a clearer picture of diet-induced dopamine changes in both obese and nonobese individuals and to unravel the mechanisms through which an obesogenic diet exerts its action on 
the dopamine system (see Box 1 for potential mechanistic links). To translate findings from animal studies to human studies, it is crucial to increase convergence between the two fields. First, human studies with dietary interventions and dopamine measurements are needed. Second, diets in animal intervention studies should be more carefully designed in terms of composition and duration to mimic human obesogenic diets. Finally, a recent review emphasises the importance of the element of dietary choice in modelling the characteristics of human diet-induced obesity [109].

\section{Metabolic factors interacting with dopamine}

Endogenous homeostatic hormones, nutrients from the bloodstream such as triglycerides and inflammatory factors connect dopamine and obesity. They are related to adipose tissue and obesity and can also affect mesolimbic brain structures and thus dopamine-mediated cognitive function and reward processes. Below, examples are discussed of how insulin, leptin, ghrelin and inflammation factors may interact with dopamine, without aiming to be comprehensive. The reader is referred to recent reviews on nutritional lipids [110, 111], homeostatic and hedonic influencers on diet and obesity [112] and mechanisms of obesity-induced inflammation [113] for further information.

Insulin, Leptin and Ghrelin

In the healthy individual, various hormones are secreted into the bloodstream according to nutrient levels, satiation and nutritional state. Insulin is postprandially released from pancreatic $\beta$ cells, promotes glucose utilisation and an anabolic metabolism and suppresses appetite centrally. Leptin is synthesised and stored in adipocytes in proportion to fat mass and adipocyte size [114, 115]. In obesity, insulin and leptin are often elevated (e.g. [116]), while (central) sensitivity to them is impaired [115]. Ghrelin, a gastric peptide, promotes food intake, is secreted in the fasting state and suppressed postprandially [117] in proportion to calorie content of the meal [119]. Fasting levels of the active form, acyl ghrelin, are often lower in obesity and eating disorders [118, 119], and levels decrease less after meals [118, 120]. Impaired insulin sensitivity might mediate this effect, independent of BMI [121].

For homeostatic functions, as well as regulation of food intake, the ability of insulin, leptin and ghrelin to cross the blood-brain barrier and bind to hypothalamic receptors is crucial [122]. Also, neurons in dopaminergic areas, e.g. ventral tegmental area (VTA), express receptors for leptin, insulin [123] and ghrelin [117, 124] thereby allowing for modulation of dopamine signalling. For instance, insulin-receptor binding in VTA reduced dopamine release in nucleus accumbens and induced long-term depression of excitatory synapses in rodents [125], which was proposed to explain previous findings of insulin-mediated inhibition of feeding and food seeking. Another link between insulin and dopamine exists in striatal insulin-receptor expressing interneurons that have been shown to modulate dopamine release in response to insulin stimulation [126]. Furthermore, peripheral insulin sensitivity correlated positively with dopamine levels in ventral striatum in human non-obese individuals [48] and, in line with that, negatively with D2R binding in obese participants [116]. Higher D2R binding may in fact reflect reduced dopamine levels. Insulin sensitivity may thus mediate obesity-related alterations in striatal dopamine levels. For a more detailed overview of insulin action in the human brain, see [127].

In addition, leptin can mediate effects of obesity on dopamine transmission (or vice versa). Leptin was found to correlate positively with BMI, as well as with D2R binding in the ventral striatum and caudate nucleus, again interpreted as reduced dopamine levels [116]. Only minutes after administration, leptin attenuated reactivity of VTA neurons to food cues [128]. In addition to a direct influence on the VTA, leptin can affect motivation for feeding via hypothalamic control over VTA [129•]. In contrast to leptin, ghrelin is associated with lower D2R binding in the ventral striatum, caudate nucleus and putamen and, in the fasting state, plays an important role in food reward sensitivity by modulating dopamine tone [116].

\section{Inflammation Factors}

Adipose tissue, notably macrophages, can secrete inflammatory cytokines, such as interleukin 6 (IL-6) or tumor necrosis factor alpha $(\mathrm{TNF}-\alpha)[130]$. As a result, chronic low-grade inflammatory state is often observed in obesity. Inflammation can lead to insulin resistance and diabetes [131], as well as dopamine changes, suggesting the possibility of a (causal) connection between inflammation and dopamine changes in obesity.

In humans, several studies investigated the effect of experimentally induced inflammation on striatal brain structures. In healthy participants, a reduction in ventral striatal activity during reward learning was observed following an increase of IL-6 [132, 133]. This led to lower reward and higher punishment sensitivity [133]. Furthermore, experimentally induced transient inflammation (IL-6, IL-8, TNF- $\alpha$ ) was shown to enhance methylphenidate-induced dopamine release in the dorsal striatum (i.e. caudate nucleus and putamen) [134]. This supraphysiologic dopamine elevation due to inflammation might lead to reduced inhibitory control resulting in higher responsiveness to potentially addictive stimuli. For an excellent review of the role of dopamine in inflammation effects on motivation and motor function in clinical and non-clinical individuals, see [135]. Inflammation can also be affected by the above-mentioned metabolic factors and, as such, influence dopamine. Dysregulated metabolic factors might therefore sustain the inflammatory state observed in obesity. Leptin is considered a pro-inflammatory cytokine and increases in response to systemic inflammation and TNF- $\alpha$ [115]. Ghrelin has been shown to instead suppress pro-inflammatory cytokines in human monocytes and T cells [136].

Finally, dopamine may also act on metabolic and inflammatory factors, with possibly differential effects depending on receptor types and tissues. Adipocytes express D2Rs, and stimulation with quinpirole (D2R agonist) in rodents elicited increased expression of leptin and IL-6 in these cells [137], which counteracts the effect of dopamine. In a rat study, bromocriptine (D2R agonist) exerted a positive effect on metabolic syndrome parameters [138].

In summary, the relationship between insulin, leptin, ghrelin and dopamine is complex. It strongly depends on caloric state, time-scale (acute vs. chronic) and involves multiple mechanisms rather than one simplistic regulatory circuit. Furthermore, inflammation factors may interact with dopamine, metabolic factors or both. 


\section{Frontostriatal Loops}

The striatum shares major connections with regions in the frontal cortex that are strongly modulated by dopamine and subserve adaptive behaviour. Across species, frontostriatal connections are organised in anatomically and functionally segregated loops [139-142] (Fig. 1). These loops are often grouped into three functionally relevant categories: (1) the affective loop between the ventromedial prefrontal cortex/orbitofrontal cortex ( $\mathrm{vmPFC/OFC)}$ and nucleus accumbens (NAc) in the ventral striatum is important for motivational control,

\section{External signals}

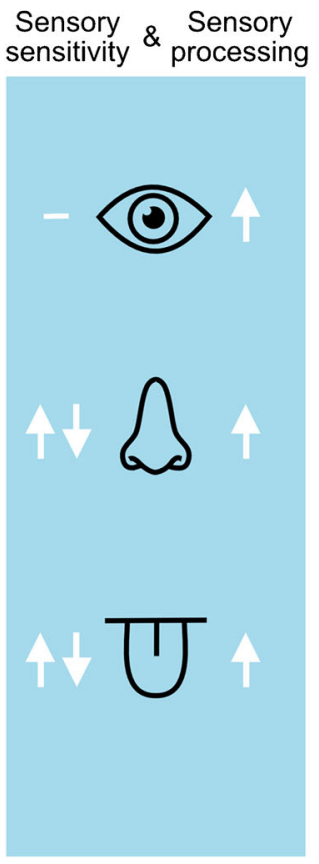

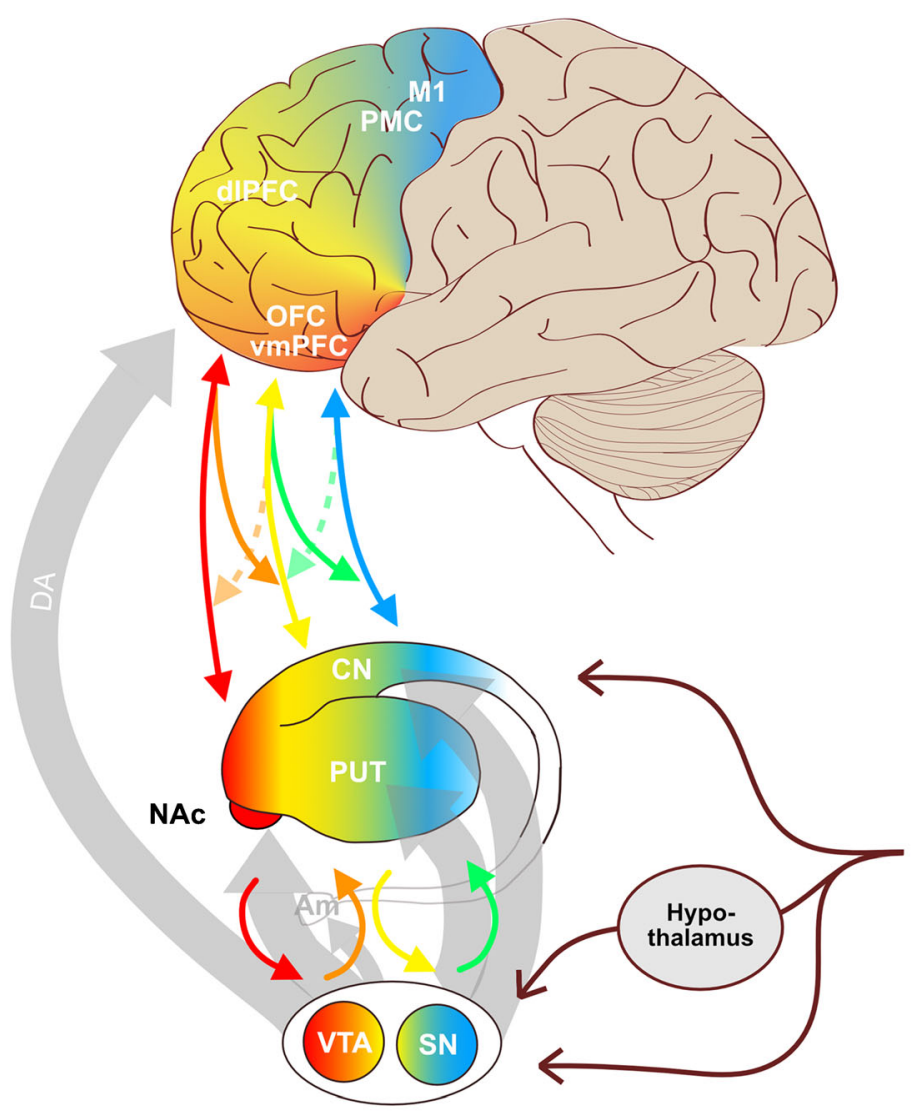

\section{Internal signals}

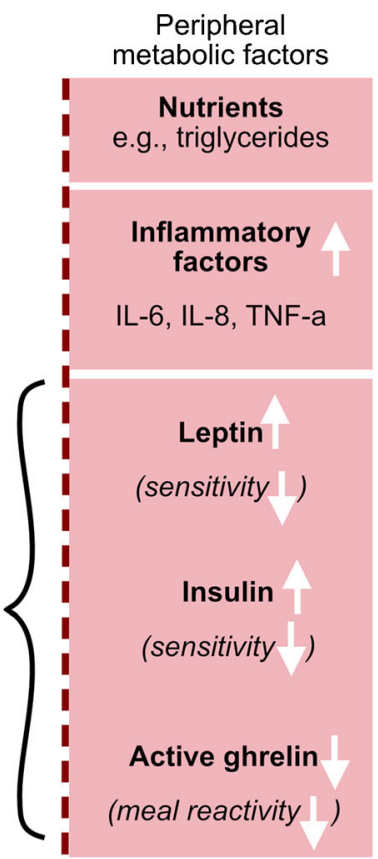

\section{Legend}

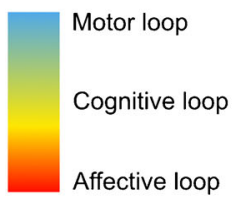

Fig. 1 Schematic overview of the frontostriatal circuit and their relationship with external and internal signals as discussed in the main text. Striato-nigro-striatal connections that can serve as the interface between the loops are also displayed. The affective loop (red) consists of connections between $\mathrm{vmPFC/OFC}$ and NAc and is predominantly modulated by dopamine projections from VTA, the cognitive loop (yellow) of connections between dIPFC and CN/aPUT and is modulated by dopamine projections from VTA and $\mathrm{SN}$, and the motor loop of connections between PMC/M1 and pPUT and is predominantly modulated by dopamine projections from $\mathrm{SN}$. The color gradient between the loops reflects the shared connections that enable cross-talk between all loops. Dopamine projections are highlighted by thick grey arrows.

$\begin{array}{llll}\text { Am } & \text { Amygdala } & \text { dIPFC } & \text { Dorsolateral Prefrontal Cortex } \\ \text { CN } & \text { Caudate Nucleus } & \text { M1 } & \text { Primary Motor Cortex } \\ \text { NAC } & \text { Nucleus Accumbens } & \text { PMC } & \text { Premotor Cortex } \\ \text { PUT } & \text { Putamen } & \text { OFC } & \text { Orbitofrontal Cortex } \\ & & \text { vmPFC } & \text { Ventromedial Prefrontal Cortex } \\ \text { SN } & \text { Substantia nigra } & & \\ \text { VTA } & \text { Ventral Tegmental Area } & & \end{array}$

External signals that affect the frontostriatal circuit in the context of food include visual, olfactory and gustatory sensory signals (left panel, in blue). Adaptations in sensory sensitivity (left white arrows) and subsequent processing, or cue reactivity (right white arrows), have been associated with obesity. Important internal signals that can affect the circuit include nutrients, inflammatory factors, and hormones such as leptin, insulin and ghrelin (right panel, in red). Adaptations in leptin, insulin and active ghrelin (in fasting state) have been observed in obesity, as well as in central sensitivity to these hormones (white arrows). Leptin, insulin and ghrelin can modulate the frontostriatal circuit through action on receptors in striatum, in VTA directly, or indirectly via hypothalamic control of VTA 
(2) the cognitive loop between the dorsolateral prefrontal cortex (dlPFC) and caudate nucleus (CN) and anterior putamen (aPUT) in the dorsomedial striatum is important for cognitive control and (3) the motor loop between the (pre) motor cortex (PMC/M1) and posterior putamen (pPUT) in the dorsolateral striatum is important for motor control. The loops also share substantial connections to enable information transfer from ventromedial to dorsolateral loops [141-143]. The different striatal regions may, in addition, receive input from prefrontal areas outside of their loop as was recently shown in a primate study [143], enabling cross-talk between all loops.

Dopamine-dependent plasticity is thought to underlie reward-based learning in all loops [141], although dopamine has also been proposed as the interface between the loops through the striato-nigro-striatal connections [142]. As reviewed above, obesity- and diet-related changes in dopamine have been consistently shown in the ventral and dorsal striatum. However, dopamine is suggested to not only modulate learning and motivated behaviour through its effect on striatal output, but also by its effect on input coming from the PFC or sensory regions, as discussed next. Evidence of obesity-related dopamine changes in PFC is scarce, due to difficulty imaging prefrontal dopamine (but see a new PET development by $[144,145 \cdot])$ and due to the ongoing debate on what are the rodent homologues of the prefrontal cortex [146].

\section{Dopamine Modulation of Sensory Inputs}

Dopamine modulates sensory perception and processing $[43 \bullet \bullet, 91,92]$. Since sensory perception, in particular visual, gustatory and olfactory perception, influences when, how much and what we eat $[147,148]$, dopamine might play a key role in influencing food choice via this route as well.

There is solid evidence that obesity is accompanied with alterations in especially the gustatory and olfactory systems. However, as the results are contradictory, the direction and interpretation of this relationship remains unclear. For instance, some researchers show higher gustatory sensitivity [38, 149]; others lower gustatory sensitivity or no difference in obese when compared to normal-weight individuals [39, 150, 151]. Similarly, it has been shown that obese participants had higher [152] or lower olfactory sensitivity [36, 37].

Of note, the olfactory and dopamine systems are highly interconnected and are therefore of particular interest in the context of eating behaviour and obesity. It has been shown that food odour perception activates dopaminergic brain regions in a human fMRI study [93]. Moreover, dopamine neurons have been detected in the olfactory bulb [153] and a reduction of dopamine neurons induced olfactory impairment in an animal model [154]. Greater availability of DATs in the caudate nucleus and putamen, as measured with SPECT in healthy human individuals, has been associated with higher olfactory performance [92]. Interestingly, one study found evidence of decreased dopamine uptake in the caudate nucleus in Parkinson's disease (PD) patients with and without olfactory impairments [89]. Although PD patients constitute a particular clinical group, the results support the link between dopamine function and olfactory perception.

Beyond affecting perceptual aspects in sensory systems, dopamine modulation of sensory signals may also serve as adjusting the sensory input for the affective frontostriatal loop. As such, dopamine can affect higher-order processing of sensory input, such as hedonic value of, and cue reactivity to visual, gustatory and olfactory input. It has been shown that obese compared to normal-weight individuals perceive food odours as more pleasant [152] and have a higher food cue reactivity in response to food pictures [155] and odours [44]. There is solid evidence that increased physiological (e.g. salivation, skin conductance, neural activation) and craving responses to food-related stimuli are associated with both food consumption and body weight [138]. Such food stimuli also potently activate the brain's reward system, i.e. the striatum and PFC value areas [23, 25, 26, 93].

In conclusion, dopamine can modulate sensory input and the subsequent processing of sensory information. While enhanced reactivity of the limbic system to visual and olfactory food cues, which is likely mediated by dopamine, is quite well established in obesity, general differences in sensory sensitivity require further investigation. Whether a diet high in fat and sugar leads to similar changes through its effects on dopamine, independent of obesity or only as a result of excessive adiposity and the associated metabolic changes (Box 1), is an open question for future investigation.

\section{Neurocognitive Profile of Obesity}

Apart from distinct reactions to food and food cues, obesity has been associated with a wide variety of 
higher-order neurocognitive differences that crucially rely on dopamine action in all parts of the frontostriatal loops $[1,9]$ (Table 1). In specific tasks, impairments in executive skills including attention, (working) memory and learning [10-16] are consistently shown in obesity. In addition, reductions in cognitive flexibility [7] and increases in several types of impulsivity [156-159] seem to characterise obesity. Such general cognitive features are likely the roots that feed maladaptive decision-making in a food context.

\section{Food Reward Responses and General Reinforcement Learning}

When it comes to reward processing of food and non-food stimuli, brain regions associated with the affective loop, i.e. NAc and $\mathrm{mPFC} / \mathrm{OFC}$, are particularly involved [160], and activation patterns in these regions can depend on metabolic state [161]. As discussed above, enhanced reactivity to sensory food cues is typically observed in obesity. In simple reaction tasks where (often hypothetical) food rewards are anticipated, enhanced activation in the affective loop is observed in obesity [70], which may be mediated by decreases in leptin and insulin sensitivity (see also Box 1). When a food reward is received, however, hypoactivation is often reported (e.g. [8, 25]). Interestingly, Kroemer and Small [8] elegantly show how obesity-related hypoactivation of reward regions in response to reward receipt may be explained by impairments in general reinforcement learning, similar as proposed for substance addiction [162].

Reward-related learning within the frontostriatal loops critically relies on dopamine-dependent plasticity [141], which may go beyond reward learning and extends to associative learning ([161], preprint). The reinterpretation of the findings in a learning framework supports the idea that obesity is related to general rather than food-specific differences, and dovetails with the widespread role of dopamine in motivation, cognition and behaviour. General reinforcement learning differences in obesity, be it impairments [5, $6,58,61,74]$ or improvements ([4], Kube et al., under revision), are indeed suggested based on evidence from non-food and food-related reinforcement learning tasks. Difficulties with integrating negative feedback may be central to observed impairments $[5,6,58]$, which could result in insensitivity to the negative consequences associated with obesity.

\section{Food-Related Attentional Bias and Craving}

What happens once food-related stimuli have been registered and led to initially enhanced responses in terms of activation of affective frontostriatal regions, invoking craving, or attracting attention? In case no food is actually available or you are trying to break a habit of giving into temptations, disengaging your attention or regulation of craving may be necessary. Obese individuals show an enhanced attentional bias to food cues across different experimental paradigms and measures $([6,58,61,74]$, but see [163]), which may be due to difficulty disengaging from such stimuli. Food attentional bias has been linked to striatal DAT binding, although no relationship was observed between DAT binding and craving or ad libitum food intake [90•]. Furthermore, glucose intake enhanced attentional food bias in obesity [41] and intra-individual variability in a similar bias measure was stronger in obesity [64], supporting the dynamic nature of attentional bias [164•]. Food attentional bias can be attenuated by cognitive factors such as a healthy mindset [87], which emphasises the importance of cross-talk between the frontostriatal loops. Regulation of craving has been associated with differential activation in the putamen and functional connectivity between the putamen and dIPFC [50], also spanning the loops.

\section{Self-Control and Cost-Benefit Decision-Making}

What if food is available? Then self-control may be needed, which again requires cross-talk between the affective and cognitive loops. Exercising self-control in a food choice task involved dIPFC activity in dieting human participants, which correlated with vmPFC activity [86]. In a similar task, Medic and colleagues [67] found no evidence for a difference in vmPFC activity for overweight to severely obese participants, whereas vmPFC activity did predict subsequent consumption of, particularly, unhealthy foods at a buffet. At the level of the striatum, reduced NAc food cue reactivity was also associated with successful self-control of eating behaviour in daily life in dieting female students, as measured with experience sampling [165]. Experience sampling is a promising method that can be used in obesity research to link neurocognitive findings to maladaptive decisions in daily life. The right food choice always depends on your current state and situation, but also on possibly conflicting internal goals. Decreased goal-directed control of behaviour in a food context has also been associated with obesity $[54,55]$. 
Food often comes at a cost, which requires weighing your options. Obese individuals may be less willing to, first, pay money for plain than highly palatable food items [73]; second, exert effort to obtain food or monetary rewards $[66,166]$; and third, wait for a larger reward if a smaller immediate reward is offered simultaneously, as consistently observed in delay discounting tasks ([167-170], but see [51•]). Willingness to exert effort relies on regions in the affective loop and is particularly interesting because of its link to dopamine $[171,172]$ as well as lowgrade systemic inflammation [173], which is highly prevalent in obesity (see Box 1). A recent PET study using a highly specific D2 tracer [51•] together with measures of insulin sensitivity revealed no difference in willingness to wait (nor striatal D2R -binding) in obese relative to non-obese participants. However, greater D2R availability in obese was associated with less willingness to wait and reduced insulin sensitivity. This raises the questions whether and how striatal D2R binding and metabolic factors interact to affect temporal discounting in obesity. In another study, lower willingness to wait (i.e. steeper temporal discounting) was associated with reduced dlPFCvmPFC connectivity in obesity [169] and may thus rely on cross-talk between the affective and cognitive loop. Interestingly, thinking about how the larger later rewards can be used (i.e. future thinking) has been effective in reducing temporal discounting and food intake in obesity [174-179] and involves cognitive control areas ACC and dlPFC, as well as mPFChippocampus interaction $[180,181]$. Of note, diet effects have been consistently shown in the hippocampus [11].

\section{Behavioural Control and Action Inhibition}

It can also occur that an action has already been initiated upon perceiving a palatable food stimulus. The decision to stop such a response can happen at the level of behavioural control in the cognitive loop, or gating of motor responses. Investigations of response inhibition, tapping into the latter, revealed small obesity-related differences [45]. However, in a resting state fMRI study, disruption was observed in motorcortico-striatal networks in obesity consistent with habit formation theories [182]. More evident results have been observed using the go/no-go task, which indicated impaired performance in obesity [183]. A behavioural intervention that trained no-go responding to high-calorie food cues led to devaluation of those items in normal-weight [184, 185] and in morbidly obese participants [34, 186], as well as impulsive food choices in normal-weight individuals [184, 185]. The authors have proposed that training acts bottom-up by creating associations between no-go food items and stopping responses and reducing valuation of no-go food items (in the affective loop) [187]. A similar mechanism may explain a reduction of food intake in uncontrolled eaters after inhibitory control training [82] and of approach bias to unhealthy food cues in obesity after training automated action tendencies [42, 188].

In sum, obesity-related differences are predominantly observed in the affective and cognitive frontostriatal loops. A simple explanation could be that studies on motor gating or learning are lacking. Many of the neurocognitive constructs investigated in obesity rely on cross-talk between the loops. Studies implementing tasks that specifically investigate the interplay between the different loops may help us further. Also, more convergence in the use of experimental stimuli and task parameters in food-related neuroimaging is needed (as argued by [181]), and there is a need of inclusion of a wider BMI range in obesity studies (see Table 1). However, a more mechanistic explanation is also plausible. That is, the more ventral and medial parts of the frontostriatal circuits may be particularly vulnerable for the effects of diet and adiposity-related metabolic factors in the bloodstream. It is important to better understand the mechanism of the cross-talk between loops. That is, where in the loops can interaction occur (e.g. is the motivational signal from the affective loop to higher-order cognitive loop, or can the cognitive loop affect the state of the affective loop?) and at what point in the process can maladaptive decisions be prevented from being made?

\section{Conclusion}

Both diet and obesity affect dopaminergic transmission. However, site and direction of effects are inconsistent across species and studies. Non-specific changes are observed spanning all frontostriatal loops, from sensory input to motivated behaviour. Given the impact of peripheral signals on central dopaminergic signalling and the interaction between the frontostriatal loops, modulation of dopamine likely propagates through all loops and, thus, affects behaviour on various levels of complexity. In line with [112], we 
highlight in Box 1 that homeostatic factors have direct access to hedonic systems via dopaminergic modulation, indicating that these can be highly interdependent, going against the historical, dichotomous concept of homeostatic vs. hedonic control over eating behaviour. However, in this review, we mostly focused on the hedonic system. Interactions between the hypothalamus and the frontostriatal circuits require further investigation.

Despite the wealth of literature, it has proven difficult to evaluate the degree of convergence of findings between animal and human studies on the role of dopamine in diet-induced obesity. The main reason is the lack of studies utilising overlapping measures of dopamine and cognition in both species. Human studies are largely observational in nature and lack direct measures of dopaminergic transmission. As such, there is a great need for diet intervention studies, more longitudinal studies [13] and mechanistic studies on the relationship between dopamine and the observed neurocognitive differences, preferably linked to metabolic factors as discussed in Box 1. Further, although some attempts have been made [109], the usage of animal diets that do not closely resemble human obesogenic diets limits comparability of the effects of diet exposure, and higher-order cognition is often not studied in relation to diet-induced dopamine changes.

Due to the narrow scope of the current review, some aspects should be highlighted that were not directly addressed but are likely of high relevance for understanding diet-induced obesity. First, this review dealt with the relationship between diet-induced obesity, cognition and dopamine transmission. Although playing a central role in motivation and cognition, dopamine is not the only neurotransmitter involved. In fact, dopamine interacts closely with other systems such as the opioid, serotonin and noradrenergic system $[57,71,189,190]$. A relationship to obesity has been demonstrated for all of them. Second, most human research is cross-sectional in nature. In addiction, the existence of subsequent behavioural phases has been proposed, leading from incentive-guided towards compulsive behaviour with accompanying central changes that indicate a transition of changes from ventromedial to dorsolateral frontostriatal loops [191]. Here, we cannot tell whether group differences similarly relate to a transition-in-progress or resemble an endpoint (although a vicious cycle model has been proposed by [11]). We do not even know whether or not overweight people are prone to obesity or represent a special "subpopulation". This transitional aspect could be addressed in animal studies that longitudinally monitor changes following diet exposure or obesity induction. It would also be of interest to take into account the severity of obesity and the individual history of being obese in human studies. Moreover, inconsistent results in the literature could be related to not assessing important latent variables such as the genetic background or possible epigenetic edits induced by lifestyle or family history. Although common variation in dopaminergic genes seems not to have a direct relationship to obesity [24], its relation to cognition is well established. Thus, ignoring this information may lead to either false positives or negatives assigned to the obesity factor.

Finally, an intriguing open question that deserves attention in future research is whether or not the changes that are observed in diet-induced obesity are really maladaptive in nature. Whereas physiological, behavioural and neural differences are often interpreted as maladaptive, it may be that some actually reflect functional adaptations that could be beneficial either at the individual or population level. This would call for a more nuanced interpretation of any obesity-related differences.

Acknowledgements The authors would like to thank Maria Kobel, Eileen Lashani, Suse Prejawa and Robert Scholz for valuable input to the manuscript.

Funding Open access funding provided by Max Planck Society. This work was funded by the Deutsche Forschungsgemeinschaft, SFB 1052: A5 (to AH, FR, HH) and the Federal Ministry of Education and Research (BMBF), Germany, in the framework of the Integrated Research and Treatment Center Adiposity Diseases at the University of Leipzig FKZ: 01E01501 (to AH, FR, KW, LKJ, $\mathrm{MW}, \mathrm{NB}, \mathrm{NH})$. MP is funded by a project grant by the Roland Ernst Stiftung.

\section{Compliance with Ethical Standards}

Conflict of Interest All authors declare that they have no conflict of interest.

Human and Animal Rights and Informed Consent This article does not contain any studies with human or animal subjects performed by any of the authors. 


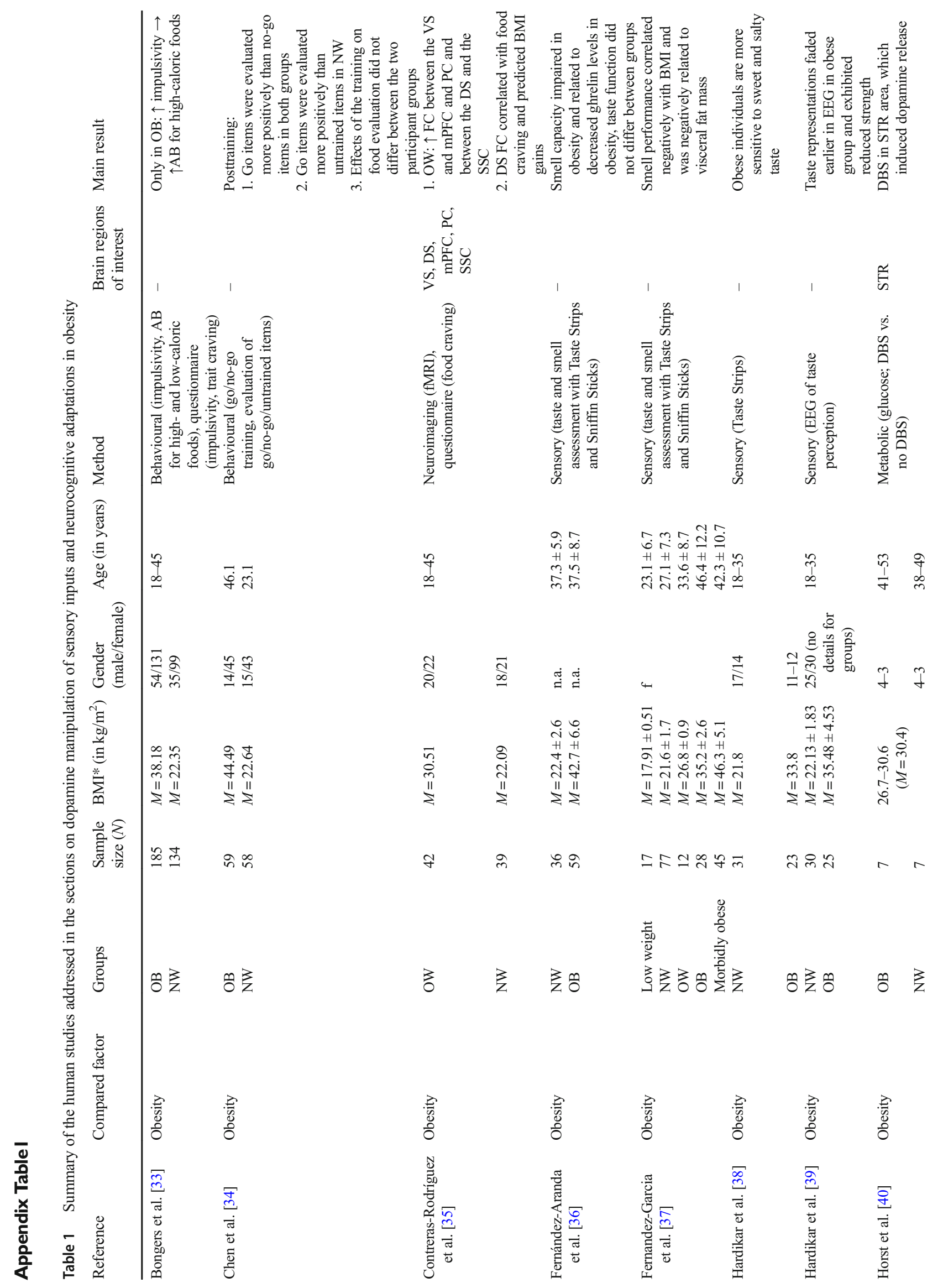




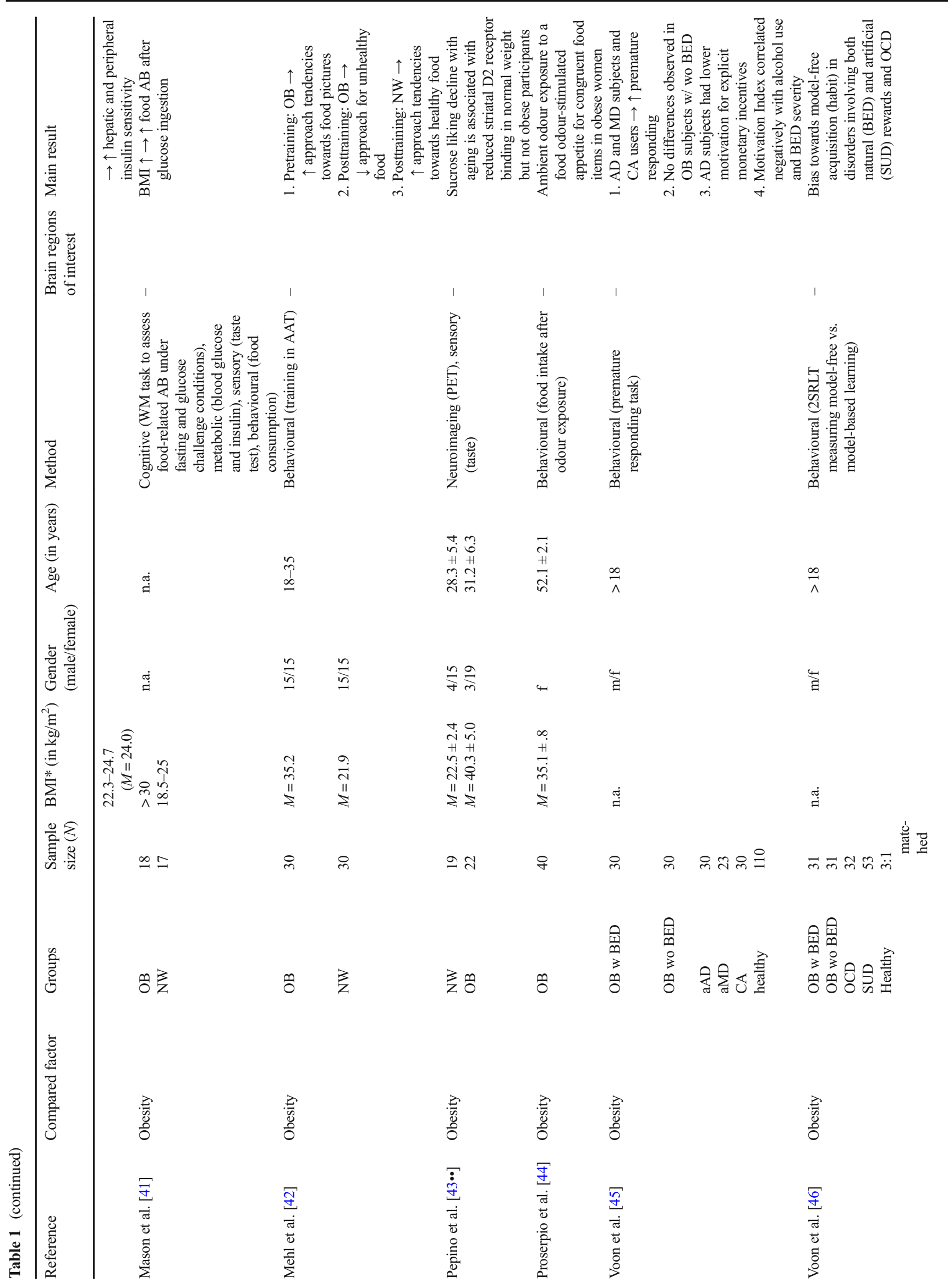




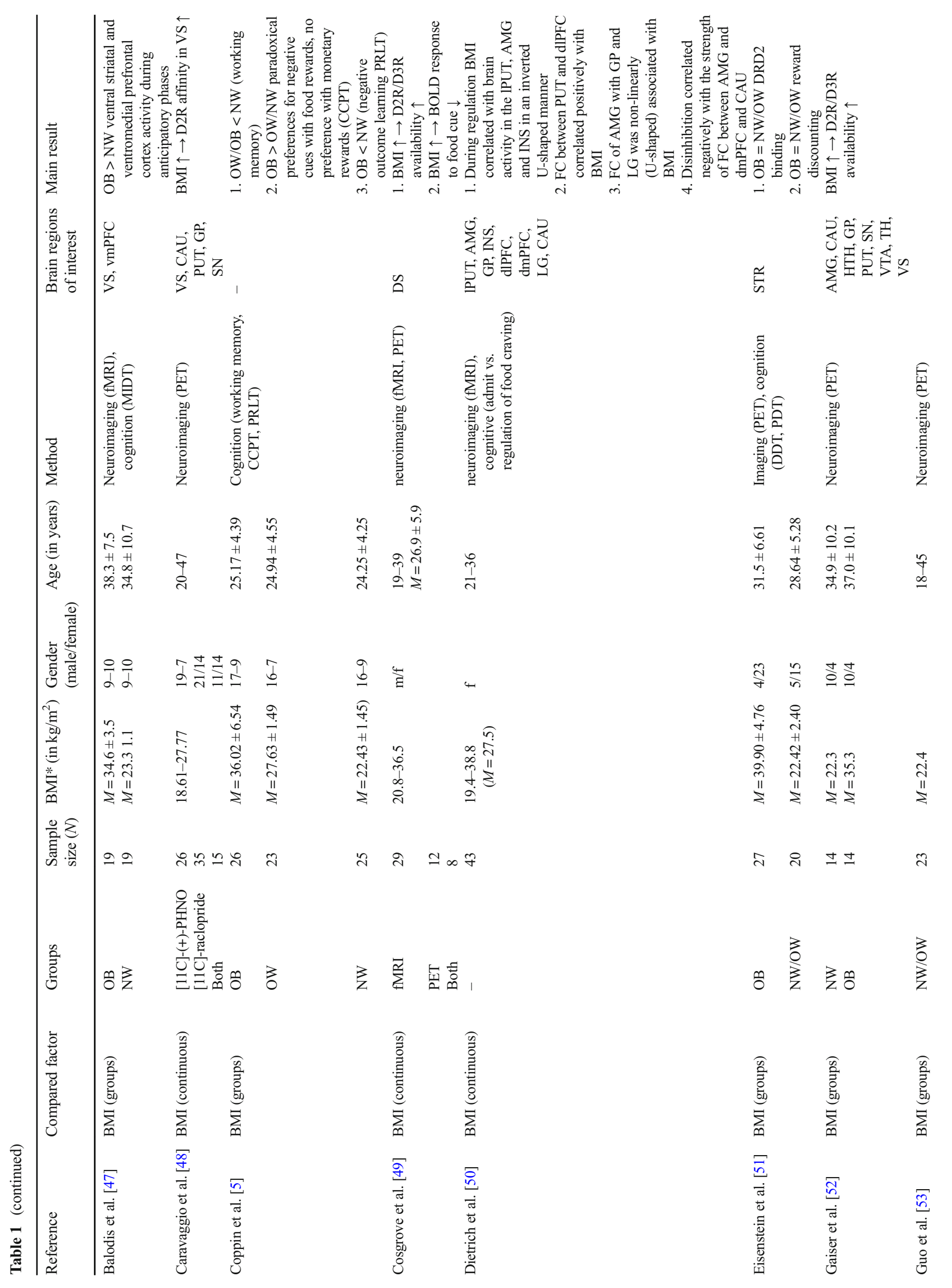




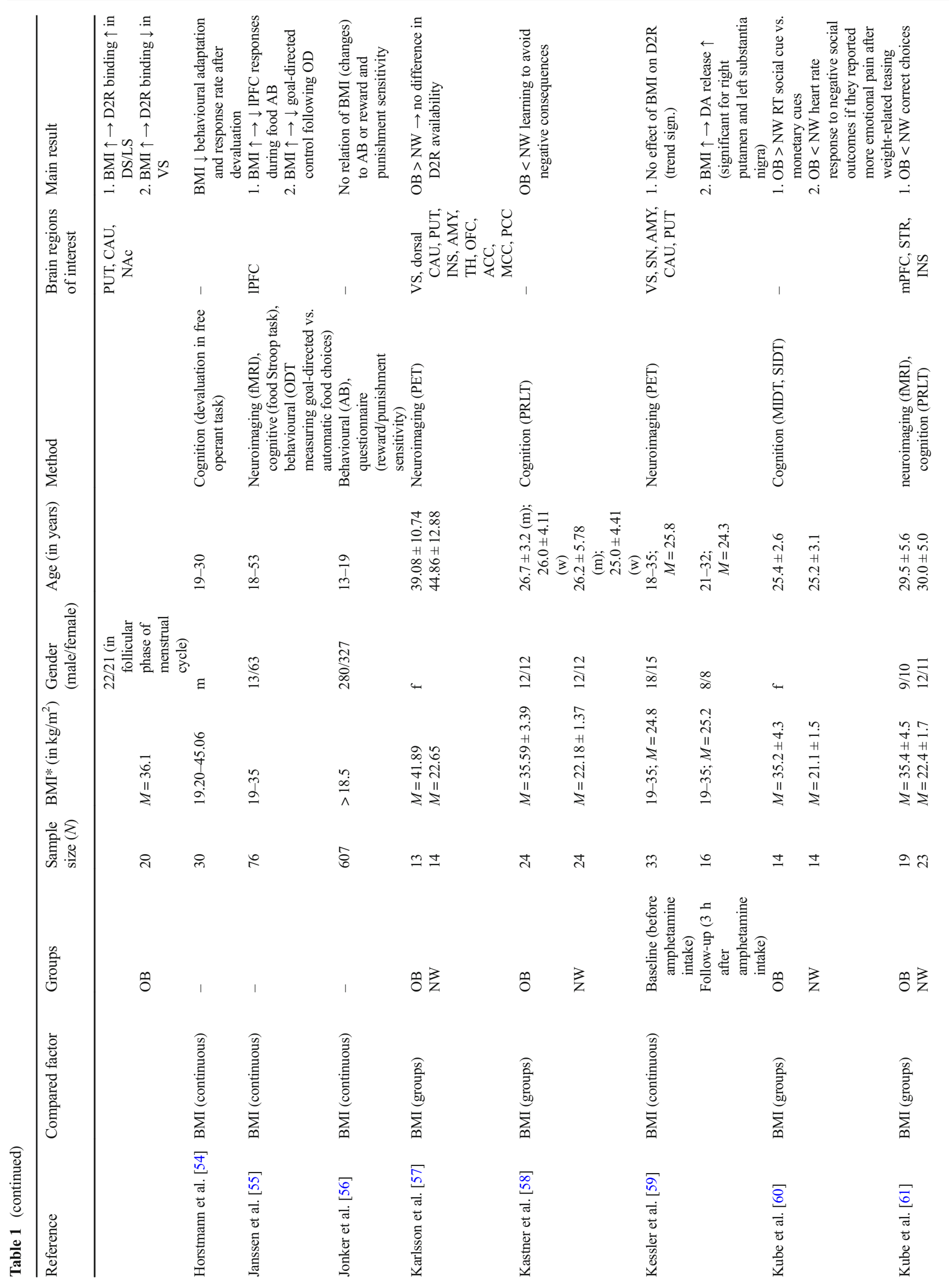




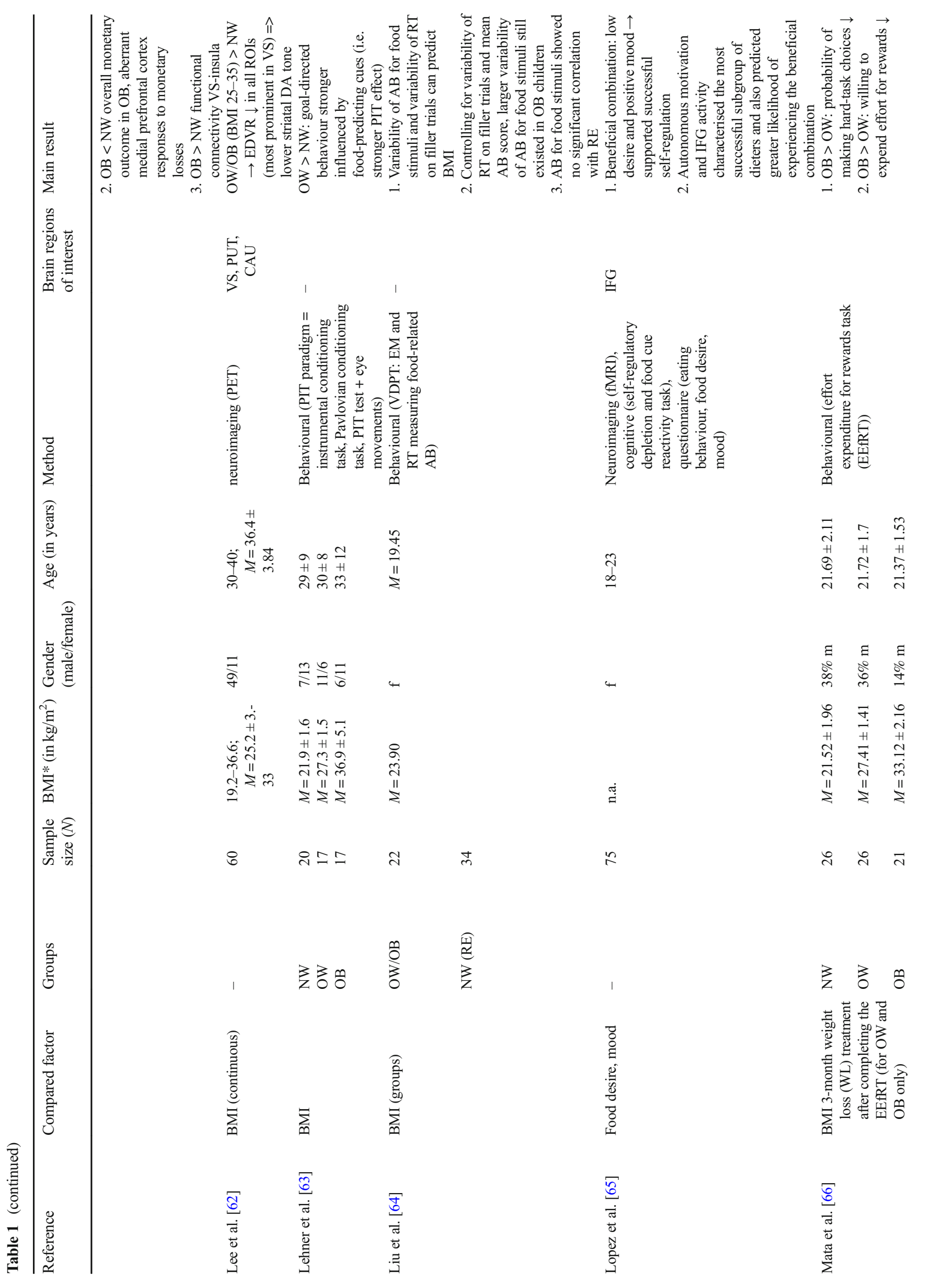




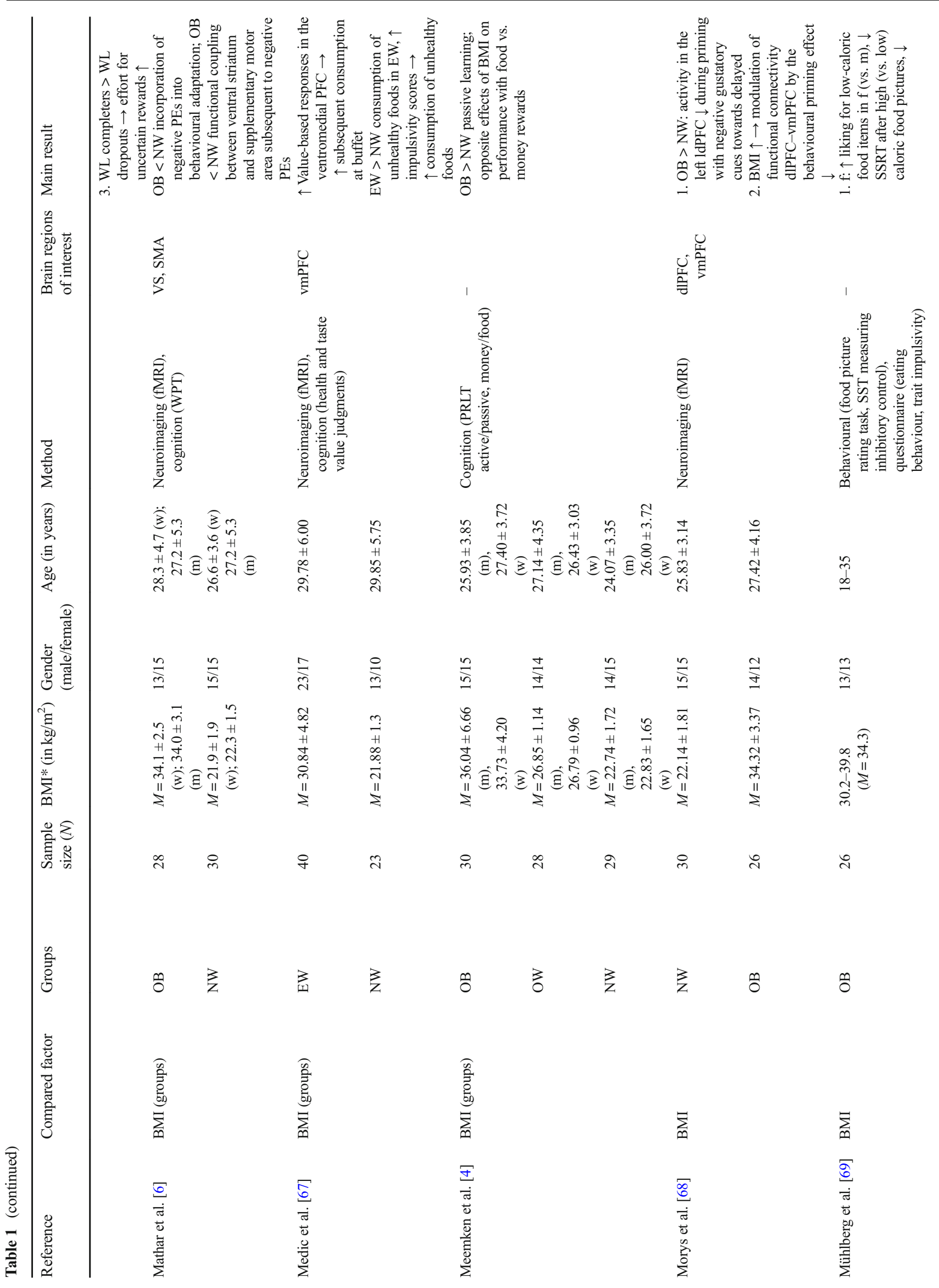




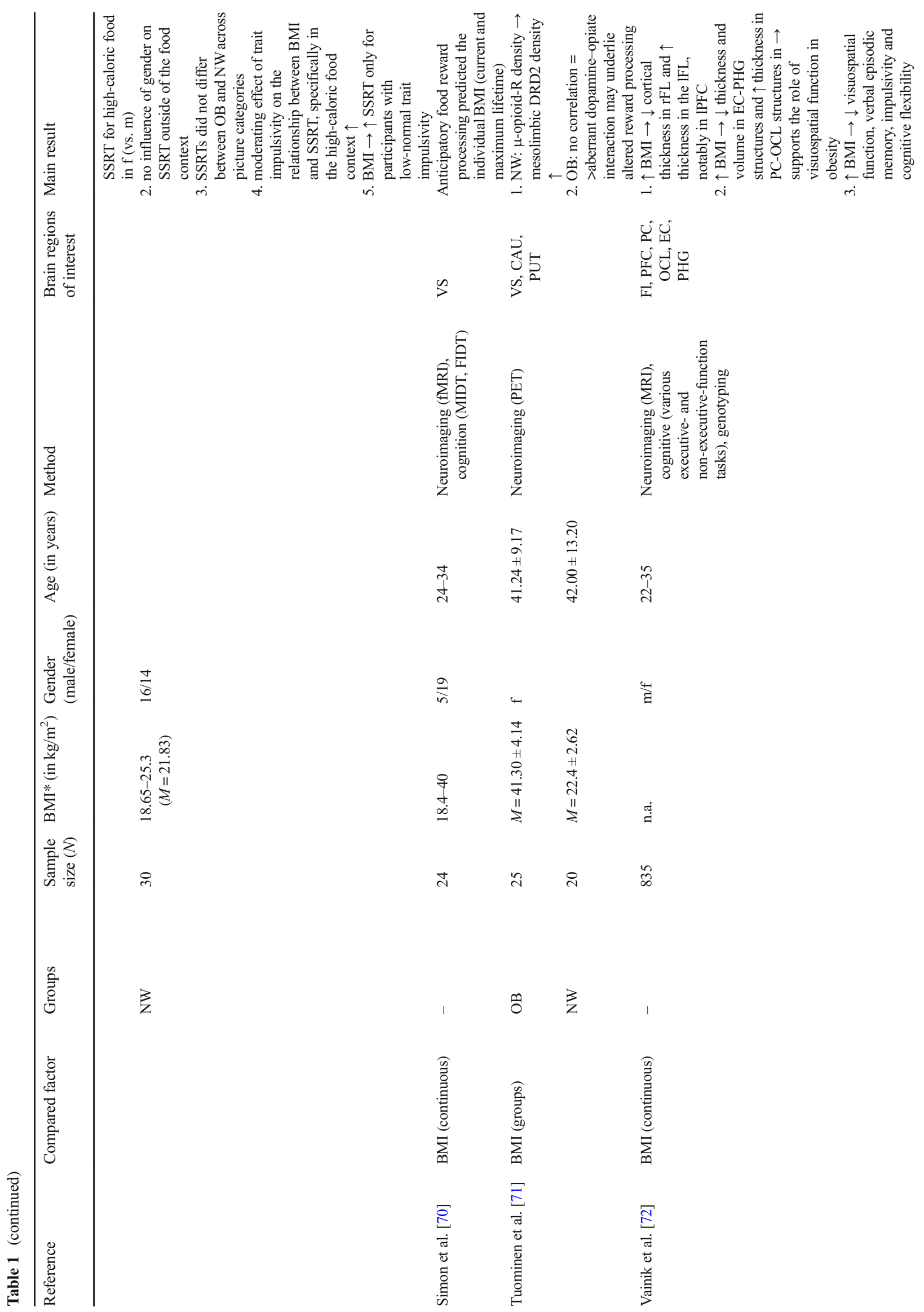




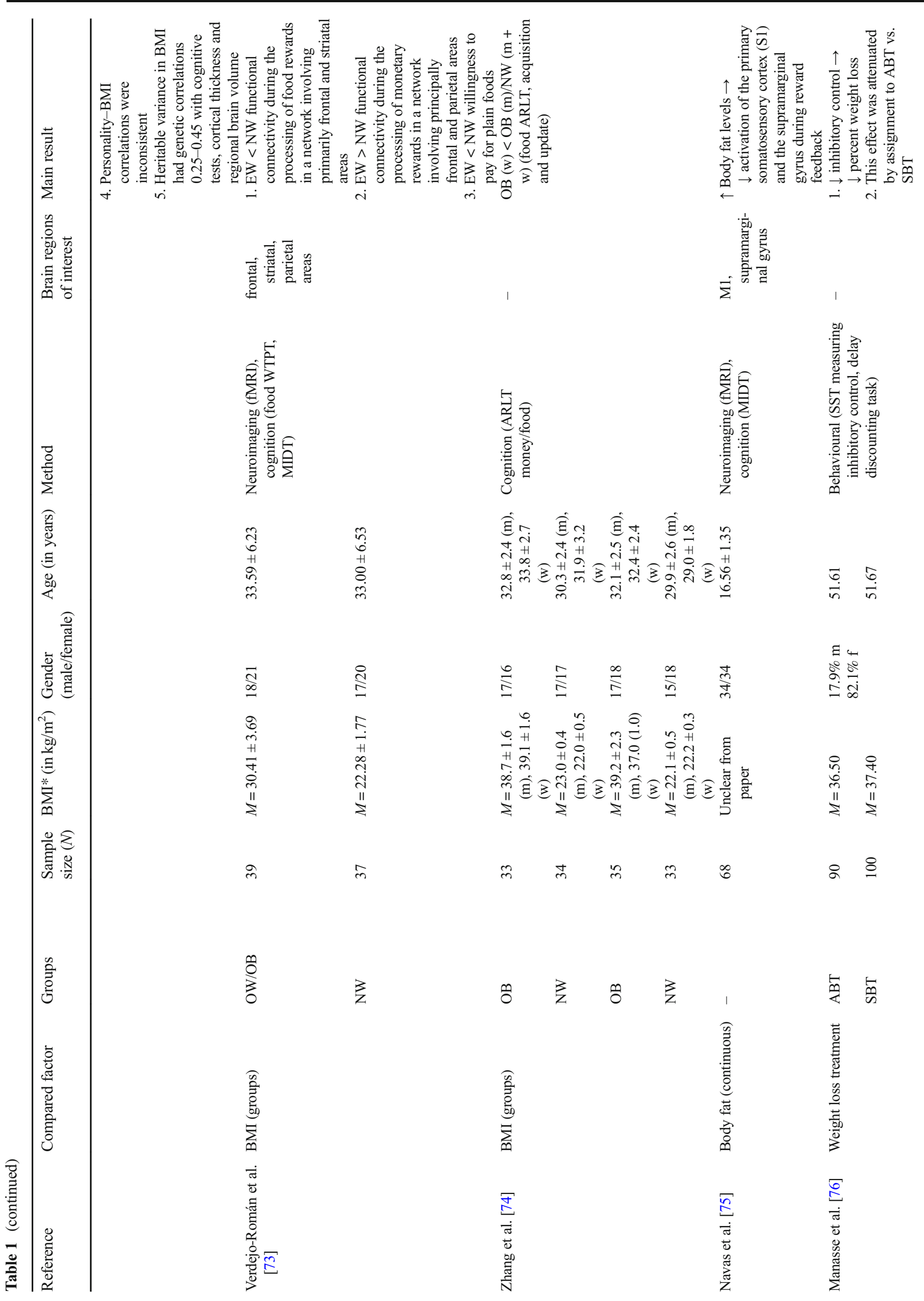




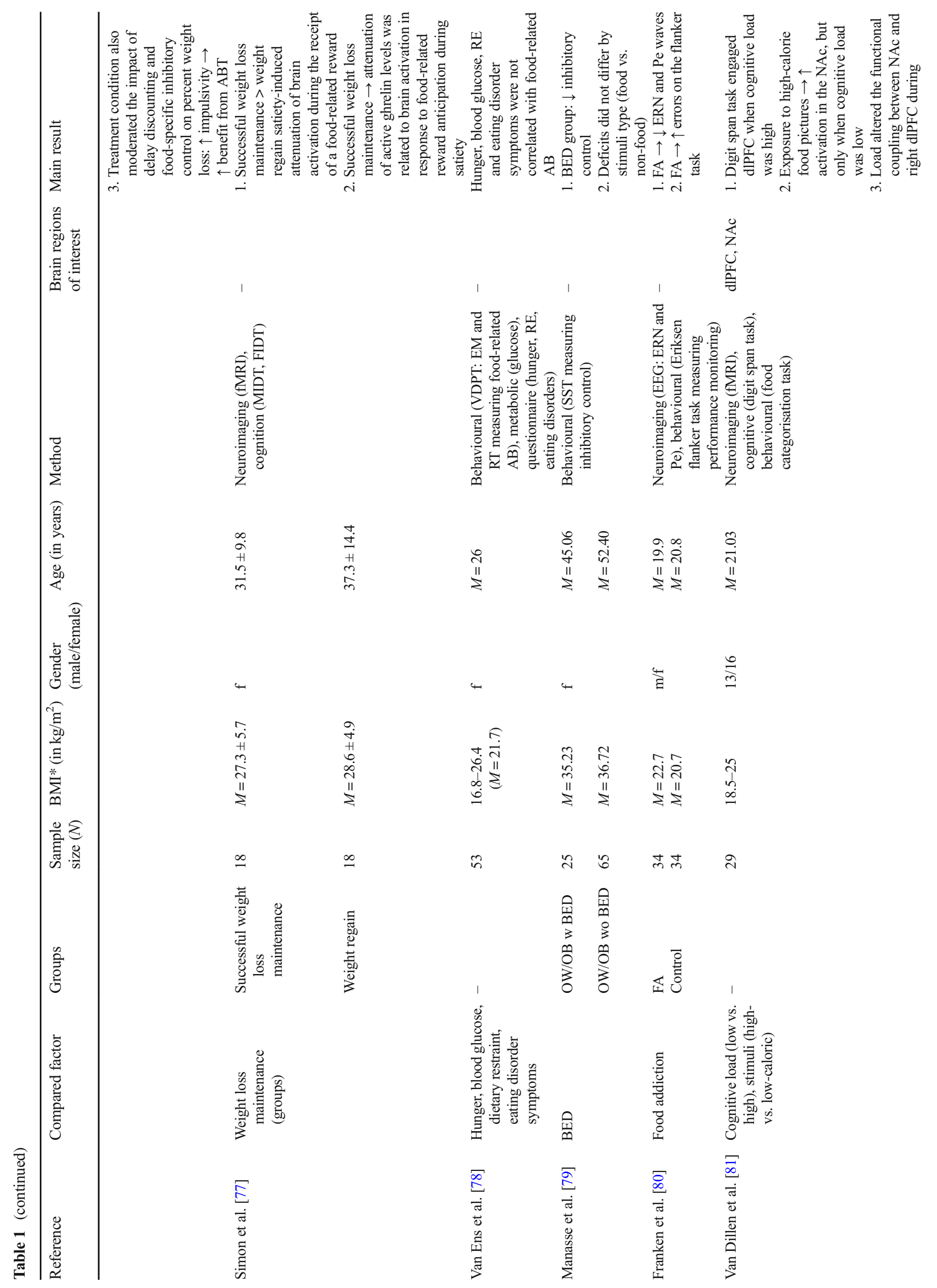




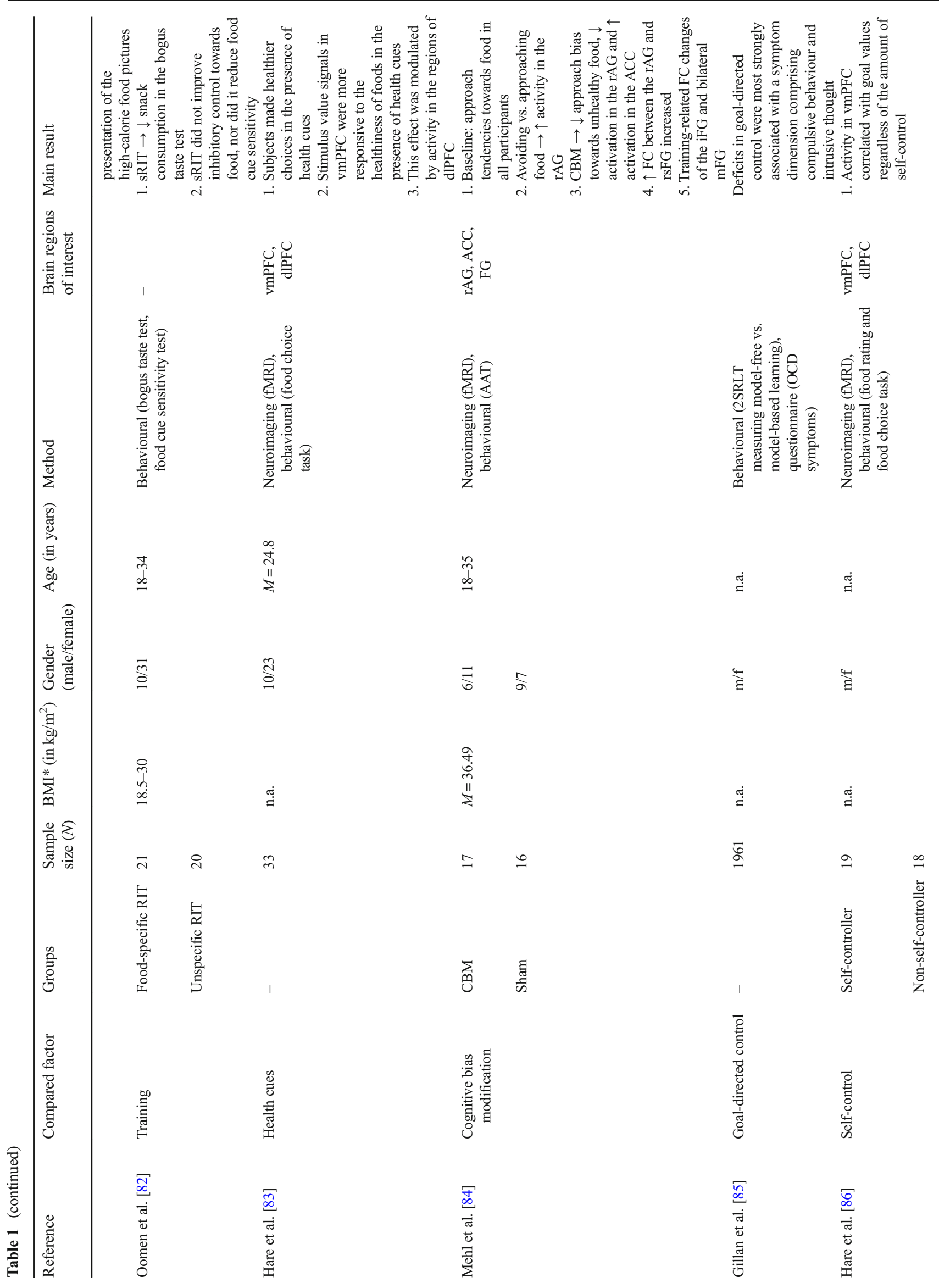




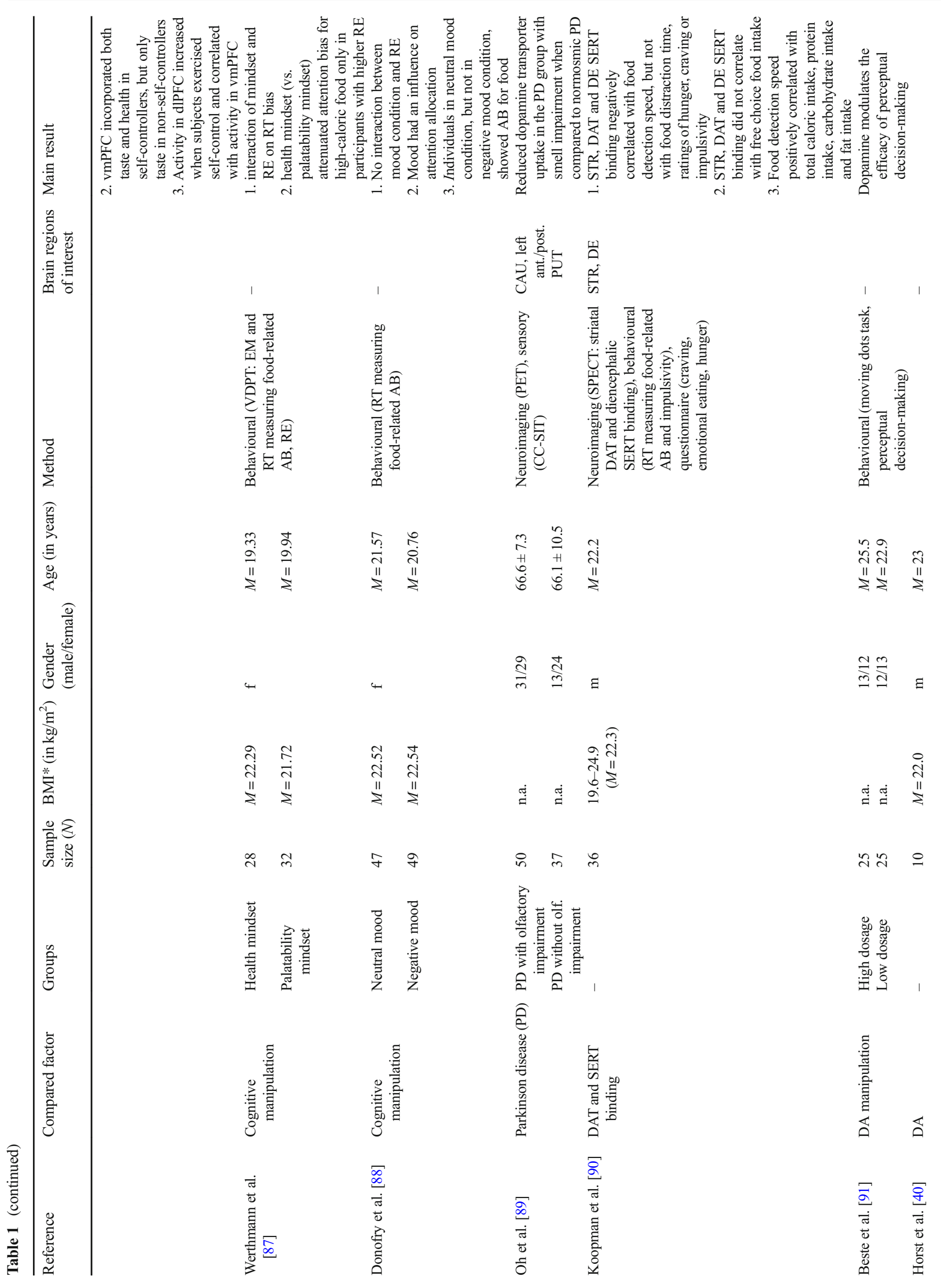




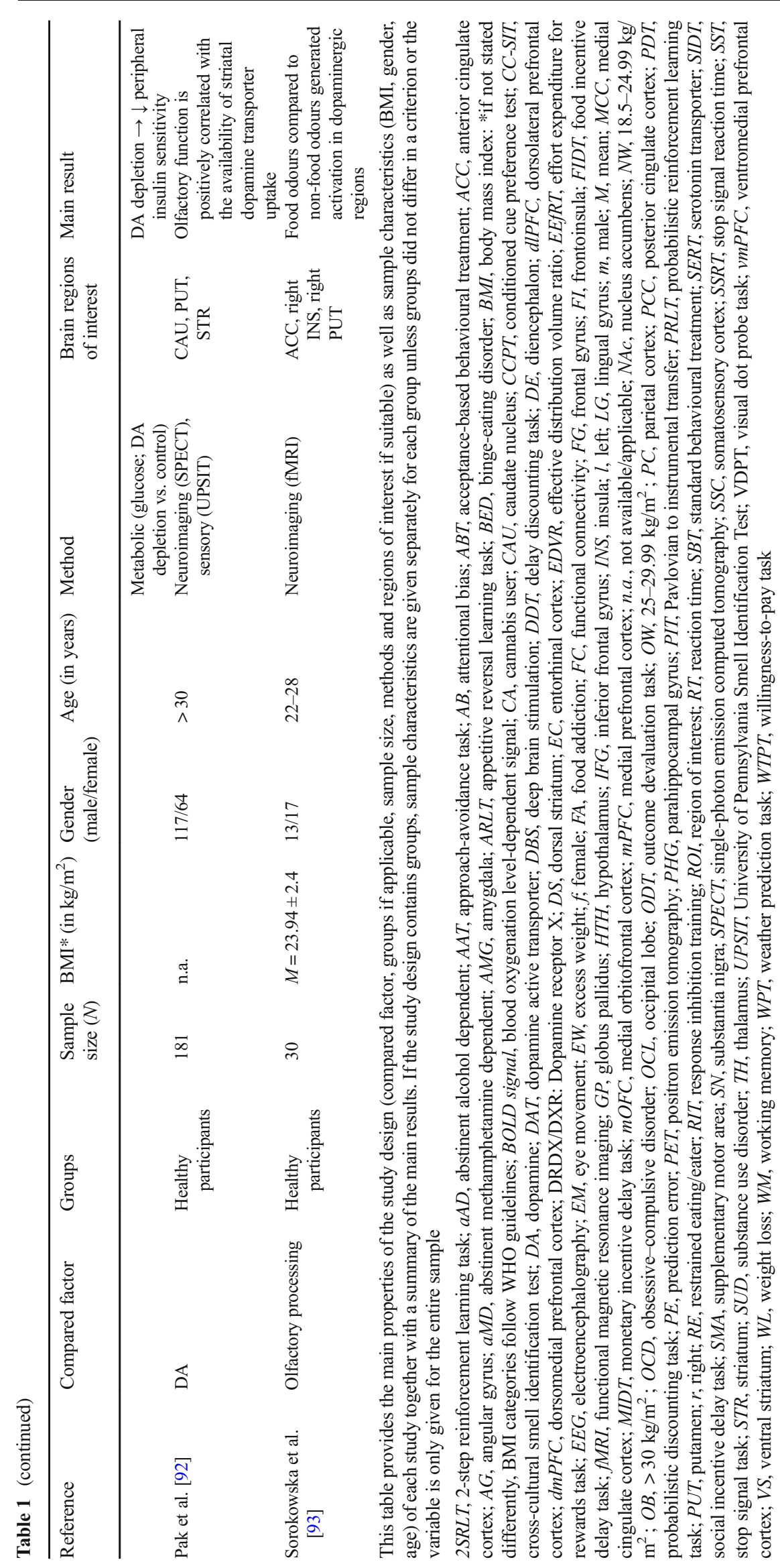




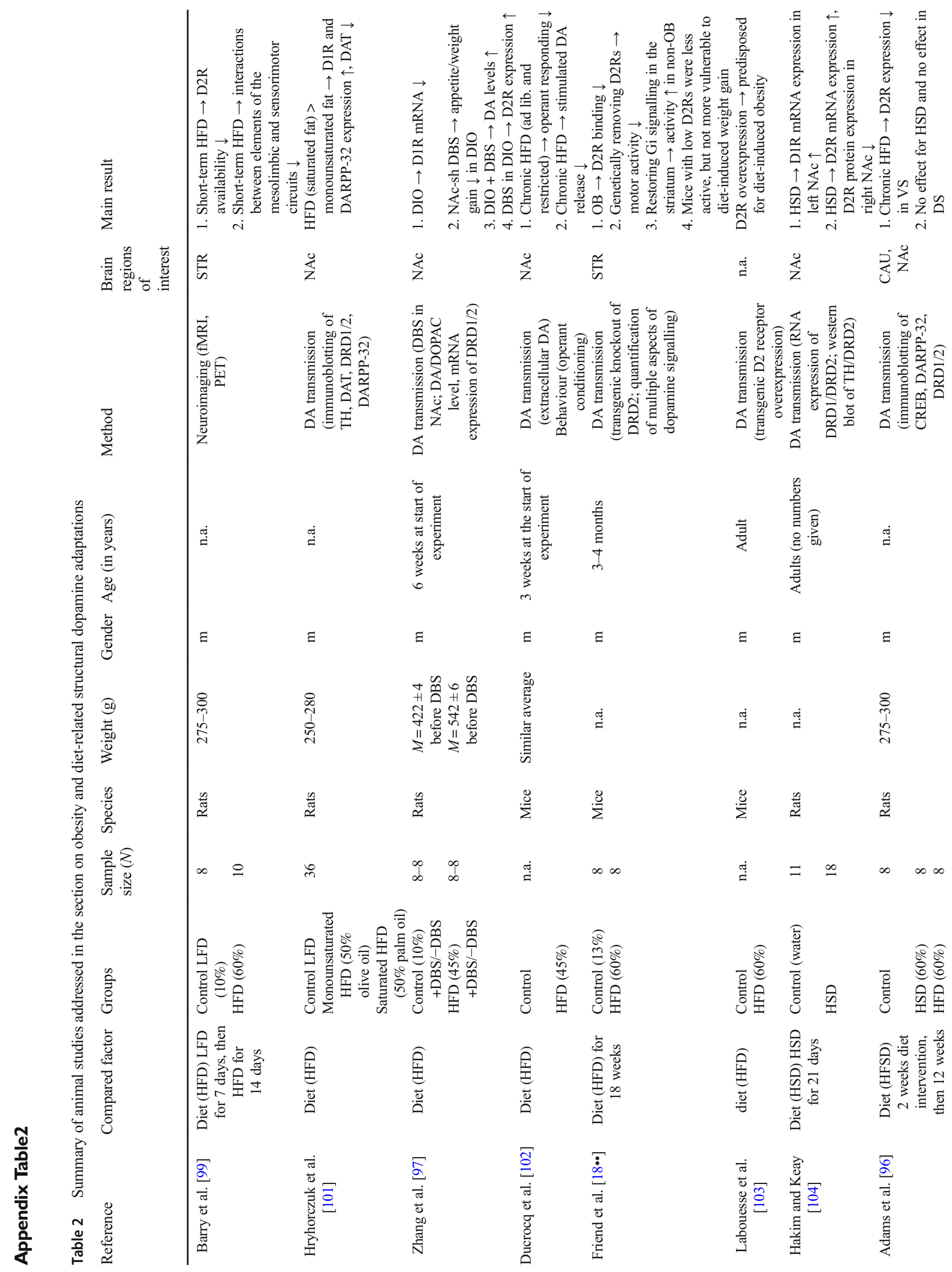




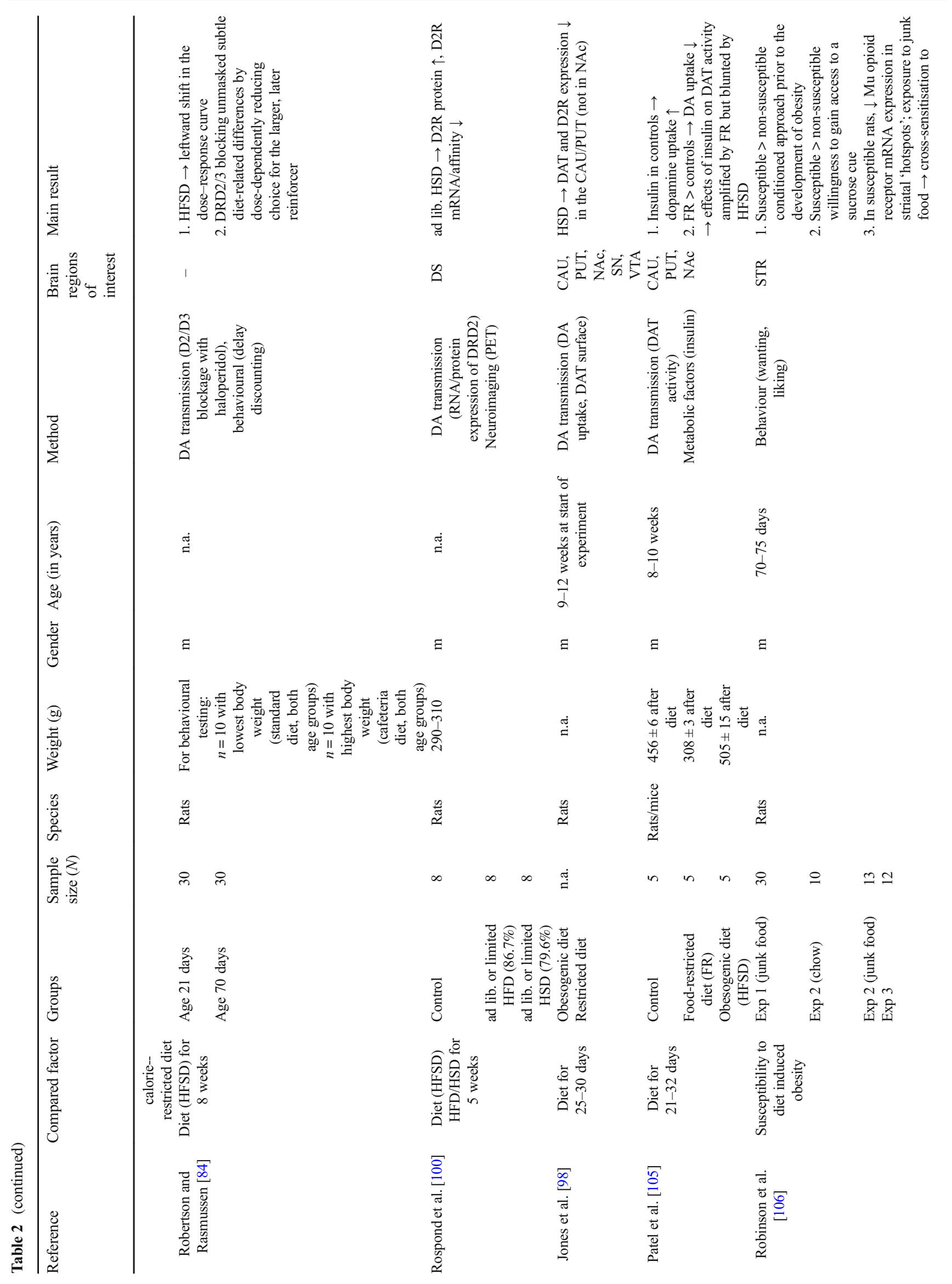




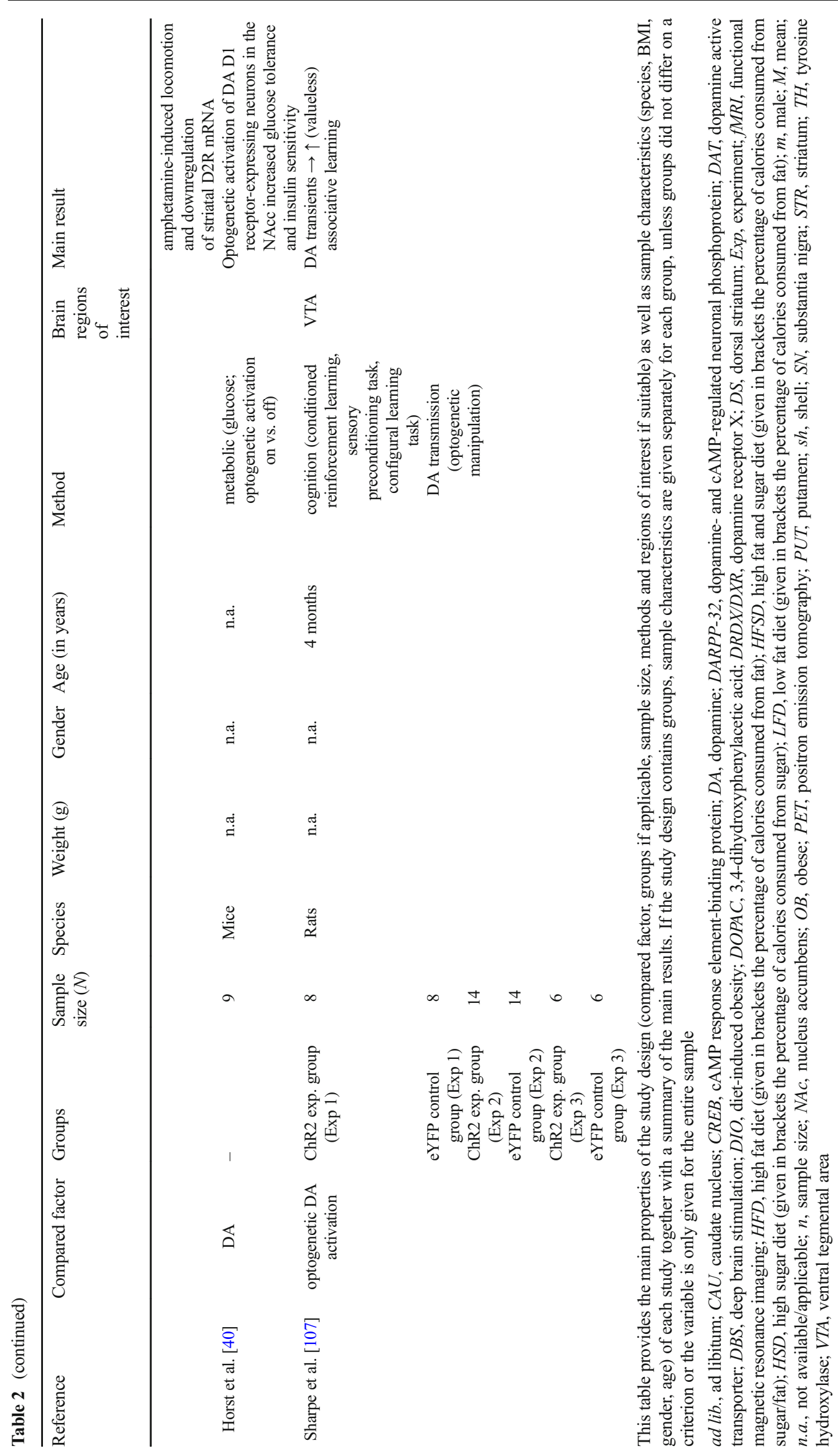




\section{References}

Papers of particular interest, published recently, have been highlighted as:

- Of importance

- Of major importance

1. Volkow ND, Wise RA, Baler R. The dopamine motive system: implications for drug and food addiction. Nat Rev Neurosci. Nature Publishing Group, a division of Macmillan Publishers Limited. All Rights Reserved. 2017;18:741.

2. Horstmann A, Fenske WK, Hankir MK. Argument for a nonlinear relationship between severity of human obesity and dopaminergic tone. Obes Rev. 2015;16:821-30.

3. Matikainen-Ankney BA, Kravitz AV. Persistent effects of obesity: a neuroplasticity hypothesis. Ann N Y Acad Sci. John Wiley \& Sons, Ltd (10.1111). 2018;1428:221-39.

4. Meemken MT, Kube J, Wickner C, Horstmann A. Keeping track of promised rewards: obesity predicts enhanced flexibility when learning from observation. Appetite. 2018;131:117-24.

5. Coppin G, Nolan-Poupart S, Jones-Gotman M, Small DM. Working memory and reward association learning impairments in obesity. Neuropsychologia. 2014;65:146-55.

6. Mathar D, Neumann J, Villringer A, Horstmann A. Failing to learn from negative prediction errors: obesity is associated with alterations in a fundamental neural learning mechanism. Cortex. 2017;95:222 37.

7. Kakoschke N, Aarts E, Verdejo-García A. The cognitive drivers of compulsive eating behavior. Front Behav Neurosci. 2019;12:338.

8. Kroemer NB, Small DM. Fuel not fun: reinterpreting attenuated brain responses to reward in obesity. Physiol Behav. 2016;162:37-45.

9. Horstmann A. It wasn't me; it was my brain —obesity-associated characteristics of brain circuits governing decision-making. Physiol Behav. 2017;176:125-33.

10. Lowe CJ, Reichelt AC, Hall PA. The prefrontal cortex and obesity: a health neuroscience perspective. Trends Cogn Sci. 2019;23:349-61.

11. Yeomans MR. Adverse effects of consuming high fat-sugar diets on cognition: implications for understanding obesity. Proc Nutr Soc. 2017. Cambridge University Press;2017:1-11.

12. Small DM. Dopamine adaptations as a common pathway for neurocognitive impairment in diabetes and obesity: a neuropsychological perspective. Front Neurosci. 2017;11:134.

13. Smith E, Hay P, Campbell L, Trollor JN. A review of the association between obesity and cognitive function across the lifespan: implications for novel approaches to prevention and treatment. Obes Rev. John Wiley \& Sons, Ltd (10.1111). 2011;12:740-55.

14. Sellbom KS, Gunstad J. Cognitive function and decline in obesity. J Alzheimer's Dis IOS Press. 2012;30:S89-95.

15. Jansen A, Houben K, Roefs A. A cognitive profile of obesity and its translation into new interventions. Front Psychol Frontiers. 2015;6: 1807.

16. Vainik U, Dagher A, Dubé L, Fellows LK. Neurobehavioural correlates of body mass index and eating behaviours in adults: a systematic review. Neurosci Biobehav Rev. 2012/12/19. 2013;37: 279-99.

17. Geiger BM, Haburcak M, Avena NM, Moyer MC, Hoebel BG, Pothos EN. Deficits of mesolimbic dopamine neurotransmission in rat dietary obesity. Neuroscience. Elsevier. 2009;159:1193-9.

18.• Friend DM, Devarakonda K, O'Neal TJ, Skirzewski M, Papazoglou I, Kaplan AR, et al. Basal ganglia dysfunction contributes to physical inactivity in obesity. Cell Metab. 2017;25: 312-21 This study shows that diet-induced obesity can cause reductions in striatal D2Rs in mice, rather than vice versa.
19. Narayanaswami V, Thompson AC, Cassis LA, Bardo MT, Dwoskin LP. Diet-induced obesity: dopamine transporter function, impulsivity and motivation. Int J Obes Nature Publishing Group. 2013;37:1095-103.

20. Van de Giessen E, La Fleur SE, Eggels L, De Bruin K, Van Den Brink W, Booij J. High fat/carbohydrate ratio but not total energy intake induces lower striatal dopamine D2/3 receptor availability in diet-induced obesity. Int J Obes Nature Publishing Group. 2013;37:754-7.

21. Vucetic Z, Carlin JL, Totoki K, Reyes TM. Epigenetic dysregulation of the dopamine system in diet-induced obesity. J Neurochem Wiley Online Library. 2012;120:891-8.

22. van de Giessen E, Mcllwrick S, Veltman D, van den Brink W, Booij J. Obesity an addiction? Imaging of neurotransmitter systems in obesity. In: D RAJO, Otte A, de Vries, EFJ, van Waarde A, den Boer JA, editors. PET SPECT psychiatry. Berlin: Springer; 2014. p. 641-656.

23. García-García I, Horstmann A, Jurado MA, Garolera M, Chaudhry SJ, Margulies DS, et al. Reward processing in obesity, substance addiction and non-substance addiction. Obes Rev. 2014;15:853-69.

24. Benton D, Young HA. A meta-analysis of the relationship between brain dopamine receptors and obesity: a matter of changes in behavior rather than food addiction [quest]. Int $\mathrm{J}$ Obes. Macmillan Publishers Limited. 2016. 40:S12-21.

25. Burger KS, Stice E. Variability in reward responsivity and obesity: evidence from brain imaging studies. Curr Drug Abuse Rev. 2011;4:182-9.

26. Stice E, Burger K. Neural vulnerability factors for obesity. Clin Psychol Rev. 2019;68:38-53.

27. DiFeliceantonio AG, Small DM. Dopamine and diet-induced obesity. Nat Neurosci. 2019;22:1-2.

28. Fletcher PC, Kenny PJ. Food addiction: a valid concept? Neuropsychopharmacology. 2018;43(13):2506-13.

29. Hebebrand J, Albayrak Ö, Adan R, Antel J, Dieguez C, de Jong J, et al. "Eating addiction", rather than "food addiction", better captures addictive-like eating behavior. Neurosci Biobehav Rev. 2014;47:295-306.

30. Pursey KM, Davis C, Burrows TL. Nutritional aspects of food addiction. Curr Addict Reports. 2017;4:142-50.

31. Avena NM, Gold JA, Kroll C, Gold MS. Further developments in the neurobiology of food and addiction: update on the state of the science. Nutrition Elsevier. 2017;28:341-3.

32. Gluck ME, Viswanath P, Stinson EJ. Obesity, appetite, and the prefrontal cortex. Curr Obes Rep. Springer. 2017;6:380-8.

33. Bongers $\mathrm{P}$, van de Giessen E, Roefs A, Nederkoorn C, Booij J, van den Brink W, et al. Being impulsive and obese increases susceptibility to speeded detection of highcalorie foods. Heal Psychol. 2015; p. 677-85.

34. Chen Z, Veling H, de Vries SP, Bijvank BO, Janssen IMC, Dijksterhuis A, et al. Go/no-go training changes food evaluation in both morbidly obese and normal-weight individuals. J Consult Clin Psychol Am Psychol Assoc. 2018;86:980-90.

35. Contreras-Rodríguez O, Martín-Pérez C, Vilar-López R, VerdejoGarcia A. ventral and dorsal striatum networks in obesity: link to food craving and weight gain. Biol Psychiatry. 2017;81.

36. Fernández-Aranda F, Agüera Z, Fernández-García JC, GarridoSanchez L, Alcaide-Torres J, Tinahones FJ, et al. Smell-taste dysfunctions in extreme weight/eating conditions: analysis of hormonal and psychological interactions. Endocrine. 2016;51:25667.

37. Fernandez-Garcia JC, Alcaide J, Santiago-Fernandez C, RocaRodriguez M, Aguera Z, Baños R, et al. Correction: an increase in visceral fat is associated with a decrease in the taste and olfactory capacity. PLoS One. 2017;12:e173588. 
38. Hardikar S, Höchenberger R, Villringer A, Ohla K. Higher sensitivity to sweet and salty taste in obese compared to lean individuals. Appetite. 2017;111:158-65.

39. Hardikar S, Wallroth R, Villringer A, Ohla K. Shorter-lived neural taste representations in obese compared to lean individuals. Sci Rep. 2018;8:11027.

40. ter Horst KW, Lammers NM, Trinko R, Opland DM, Figee M, Ackermans MT, et al. Striatal dopamine regulates systemic glucose metabolism in humans and mice. Sci Transl Med. 2018;10: eaar3752.

41. Mason AE, Jhaveri K, Schleicher S, Almeida C, Hartman A, Wackerly A, et al. Sweet cognition: the differential effects of glucose consumption on attentional food bias in individuals of lean and obese status. Physiol Behav. 2019;206:264-73.

42. Mehl N, Mueller-Wieland L, Mathar D, Horstmann A. Retraining automatic action tendencies in obesity. Physiol Behav. 2018;192: $50-8$.

43.• Pepino MY, Eisenstein SA, Bischoff AN, Klein S, Moerlein SM, Perlmutter JS, et al. Sweet dopamine: sucrose preferences relate differentially to striatal D2-receptor binding and age in obesity. Diabetes. 2016;65:2618-23 This is the first study to show that sucrose preference relates to direct measures of dopamine in human obesity.

44. Proserpio C, Invitti C, Boesveldt S, Pasqualinotto L, Laureati M, Cattaneo C, et al. Ambient odor exposure affects food intake and sensory specific appetite in obese women. Front Psychol. 2019;10:7.

45. Voon V, Irvine MA, Derbyshire K, Worbe Y, Lange I, Abbott S, et al. Measuring "waiting" impulsivity in substance addictions and binge eating disorder in a novel analogue of rodent serial reaction time task. Biol Psychiatry Elsevier. 2014;75:148-55.

46. Voon V, Derbyshire K, Ruck C, Irvine MA, Worbe Y, Enander J, et al. Disorders of compulsivity: a common bias towards learning habits. Mol Psychiatry. 2015;20:345-52.

47. Balodis IM, Kober H, Worhunsky PD, White MA, Stevens MC, Pearlson GD, et al. Monetary reward processing in obese individuals with and without binge eating disorder. Biol Psychiatry. 2013;73:877-86

48. Caravaggio F, Borlido C, Hahn M, Feng Z, Fervaha G, Gerretsen $\mathrm{P}$, et al. Reduced insulin sensitivity is related to less endogenous dopamine at D2/3 receptors in the ventral striatum of healthy nonobese humans. Int J Neuropsychopharmacol. 2015;18: pyv014.

49. Cosgrove KP, Veldhuizen MG, Sandiego CM, Morris ED, Small DM. Opposing relationships of BMI with BOLD and dopamine $\mathrm{D} 2 / 3$ receptor binding potential in the dorsal striatum. Synapse. 2015;69:195-202.

50. Dietrich A, Hollmann M, Mathar D, Villringer A, Horstmann A. Brain regulation of food craving: relationships with weight status \&amp; eating behavior. Int J Obes. 2016;40:982-9.

51. Eisenstein SA, Gredysa DM, Antenor-Dorsey JA, Green L, Arbeláez AM, Koller JM, et al. Insulin, central dopamine D2 receptors, and monetary reward discounting in obesity. PLoS One. 2015;10:e0133621 Public Library of Science. This study combines a direct measure of central dopamine (D2Rbinding, using PET) with insulin measurements and a behaviorally relevant performance measure in human obesity and, thus, bridges a large gap in the literature.

52. Gaiser EC, Gallezot J-D, Worhunsky PD, Jastreboff AM, Pittman B, Kantrovitz L, et al. Elevated dopamine D 2/3 receptor availability in obese individuals: a PET imaging study with $[11 \mathrm{C}](+)$ PHNO. Neuropsychopharmacology. Nat Publ Group. 2016;41: 3042.

53. Guo J, Simmons WK, Herscovitch P, Martin A, Hall KD. Striatal dopamine D2-like receptor correlation patterns with human obesity and opportunistic eating behavior. Mol Psychiatry. 2014/09/09. 2014;19:1078-84.

54. Horstmann A, Dietrich A, Mathar D, Pössel M, Villringer A, Neumann J. Slave to habit? Obesity is associated with decreased behavioural sensitivity to reward devaluation. Appetite. 2015;87: 175-83.

55. Janssen LK, Duif I, van Loon I, Wegman J, de Vries JHM, Cools $\mathrm{R}$, et al. Loss of lateral prefrontal cortex control in food-directed attention and goal-directed food choice in obesity. Neuroimage. 2017;146:148-56.

56. Jonker NC, Glashouwer KA, Ostafin BD, van Hemel-Ruiter ME, Smink FRE, Hoek HW, et al. Attentional bias for reward and punishment in overweight and obesity: the TRAILS study. PLoS One Public Libr Sci. 2016;11:e0157573.

57. Karlsson HK, Tuominen L, Tuulari JJ, Hirvonen J, Parkkola R, Helin $\mathrm{S}$, et al. Obesity is associated with decreased $\mu$-opioid but unaltered dopamine D2 receptor availability in the brain. J Neurosci Soc Neuroscience. 2015;35:3959-65.

58. Kastner L, Kube J, Villringer A, Neumann J. Cardiac concomitants of feedback and prediction error processing in reinforcement learning. Front Neurosci. 2017;11:598.

59. Kessler RM, Zald DH, Ansari MS, Li R, Cowan RL. Changes in dopamine release and dopamine D2/3 receptor levels with the development of mild obesity. Synapse Wiley Online Library. 2014;68:317-20.

60. Kube J, Schrimpf A, García-García I, Villringer A, Neumann J, Horstmann A. Differential heart rate responses to social and monetary reinforcement in women with obesity. Psychophysiology. 2016;53:868-79.

61. Kube J, Mathar D, Horstmann A, Kotz SA, Villringer A, Neumann J. Altered monetary loss processing and reinforcement-based learning in individuals with obesity. Brain Imaging Behav. 2018;12:1431-49.

62. Lee Y, Kroemer NB, Oehme L, Beuthien-Baumann B, Goschke T, Smolka MN. Lower dopamine tone in the striatum is associated with higher body mass index. Eur Neuropsychopharmacol. 2018;28:719-31 A particularly interesting PET-method is used to quantify dopamine tone specifically in relationship to $\mathrm{BMI}$, instead of using a D2R-binding ligand that is sensitive to D2Ravailabitility as well as dopamine tone.

63. Lehner R, Balsters JH, Bürgler A, Hare TA, Wenderoth N. Foodrredicting stimuli differentially influence eye movements and goal-directed behavior in normal-weight, overweight, and obese individuals. Front psychiatry. 2017;8:230.

64. Liu Y, Roefs A, Werthmann J, Nederkoorn C. Dynamics of attentional bias for food in adults, children, and restrained eaters. Appetite. 2019;135:86-92.

65. Lopez RB, Milyavskaya M, Hofmann W, Heatherton TF. Motivational and neural correlates of self-control of eating: a combined neuroimaging and experience sampling study in dieting female college students. Appetite. 2016.

66. Mata F, Treadway M, Kwok A, Truby H, Yücel M, Stout JC, et al. Reduced willingness to expend effort for reward in obesity: link to adherence to a 3-month weight loss intervention. Obesity. John Wiley \& Sons, Ltd. 2017;25:1676-81.

67. Medic N, Ziauddeen H, Forwood SE, Davies KM, Ahern AL, Jebb SA, et al. The presence of real food usurps hypothetical health value judgment in overweight people. Eneuro. 2016;3: ENEURO.0025-16.2016.

68. Morys F, Bode S, Horstmann A. Dorsolateral and medial prefrontal cortex mediate the influence of incidental priming on economic decision making in obesity. Sci Rep. 2018;8:17595.

69. Mühlberg C, Mathar D, Villringer A, Horstmann A, Neumann J. Stopping at the sight of food - how gender and obesity impact on response inhibition. Appetite. 2016;107:663-76. 
70. Simon JJ, Skunde M, Hamze Sinno M, Brockmeyer T, Herpertz $\mathrm{SC}$, Bendszus M, et al. Impaired cross-talk between mesolimbic food reward processing and metabolic signaling predicts body mass index. Front Behav Neurosci. 2014;8:359.

71. Tuominen L, Tuulari J, Karlsson H, Hirvonen J, Helin S, Salminen $\mathrm{P}$, et al. Aberrant mesolimbic dopamine-opiate interaction in obesity. Neuroimage. Elsevier. 2015;122:80-6.

72. Vainik U, Baker TE, Dadar M, Zeighami Y, Michaud A, Zhang Y, et al. Neurobehavioral correlates of obesity are largely heritable. Proc Natl Acad Sci. 2018;115:93127.

73. Verdejo-Román J, Vilar-López R, Navas JF, Soriano-Mas C, Verdejo-García A. Brain reward system's alterations in response to food and monetary stimuli in overweight and obese individuals. Hum Brain Mapp. 2017;38:666-77.

74. Zhang Z, Manson KF, Schiller D, Levy I. Impaired associative learning with food rewards in obese women. Curr Biol. 2014;24: 1731-6.

75. Navas JF, Barrós-Loscertales A, Costumero-Ramos V, VerdejoRomán J, Vilar-López R, Verdejo-García A. Excessive body fat linked to blunted somatosensory cortex response to general reward in adolescents. Int J Obes. Macmillan Publishers Limited, part of Springer Nature, 2018;42:88.

76. Manasse SM, Flack D, Dochat C, Zhang F, Butryn ML, Forman EM. Not so fast: the impact of impulsivity on weight loss varies by treatment type. Appetite. 2017;113:193-9.

77. Simon JJ, Becker A, Sinno MH, Skunde M, Bendszus M, Preissl $\mathrm{H}$, et al. Neural food reward processing in successful and unsuccessful weight maintenance. Obesity. John Wiley \& Sons, Ltd, 2018;26:895-902.

78. van Ens W, Schmidt U, Campbell IC, Roefs A, Werthmann J. Test-retest reliability of attention bias for food: robust eye-tracking and reaction time indices. Appetite. 2019;136:86-92.

79. Manasse SM, Goldstein SP, Wyckoff E, Forman EM, Juarascio AS, Butryn ML, et al. Slowing down and taking a second look: Inhibitory deficits associated with binge eating are not food-specific. Appetite. 2016;96:555-9.

80. Franken IHA, Nijs IMT, Toes A, van der Veen FM. Food addiction is associated with impaired performance monitoring. Biol Psychol. 2018;131:49-53.

81. van Dillen LF, van Steenbergen H. Tuning down the hedonic brain: cognitive load reduces neural responses to high-calorie food pictures in the nucleus accumbens. Cogn Affect Behav Neurosci. 2018;18:447-59.

82. Oomen D, Grol M, Spronk D, Booth C, Fox E. Beating uncontrolled eating: training inhibitory control to reduce food intake and food cue sensitivity. Appetite. Elsevier. 2018;131:73-83.

83. Hare TA, Malmaud J, Rangel A. Focusing attention on the health aspects of foods changes value signals in vmPFC and improves dietary choice. J Neurosci. 2011;31:11077-87.

84. Mehl N, Morys F, Villringer A, Horstmann A. Unhealthy yet avoidable - how cognitive bias modification alters behavioral and brain responses to food cues in individuals with obesity. Nutr Multidiscip Dig Publ Inst. 2019;11:874.

85. Gillan CM, Kosinski M, Whelan R, Phelps EA, Daw ND. Characterizing a psychiatric symptom dimension related to deficits in goal-directed control. Elife. 2016;5:e11305.

86. Hare TA, Camerer CF, Rangel A. Self-control in decision-making involves modulation of the vmPFC valuation system. Sci. 2009;324:646-8.

87. Werthmann J, Jansen A, Roefs A. Make up your mind about food: a healthy mindset attenuates attention for high-calorie food in restrained eaters. Appetite. 2016;105:53-9.

88. Donofry SD, van Zoest W, Moonen A, Sacchetti S, Nederkoorn C, Roefs A. Effect of dietary restraint and mood state on attentional processing of food cues. J Behav Ther Exp Psychiatry. 2019;62: $117-24$.
89. Oh Y-S, Kim J-S, Hwang E-J, Lyoo CH. Striatal dopamine uptake and olfactory dysfunction in patients with early Parkinson's disease. Parkinsonism Relat Disord. 2018;56:47-51.

90. Koopman KE, Roefs A, Elbers DCE, Fliers E, Booij J, Serlie MJ, et al. Brain dopamine and serotonin transporter binding are associated with visual attention bias for food in lean men. Psychol Med. 2016;46:1707-17 Cambridge University Press. This is one of the few studies that combined a direct measure of dopamine (and serotonin) using PET with food-related performance measure and food intake in healthy human participants.

91. Beste C, Adelhöfer N, Gohil K, Passow S, Roessner V, Li S-C. Dopamine modulates the efficiency of sensory evidence accumulation during perceptual decision making. Int J Neuropsychopharmacol. 2018;21:649-55.

92. Pak K, Kim K, Lee MJ, Lee JM, Kim BS, Kim S-J, et al. Correlation between the availability of dopamine transporter and olfactory function in healthy subjects. Eur Radiol. 2018;28:175660 .

93. Sorokowska A, Schoen K, Hummel C, Han P, Warr J, Hummel T. Food-related odors activate dopaminergic brain areas. Front Hum Neurosci. 2017;11.

94. Caravaggio F, Raitsin S, Gerretsen P, Nakajima S, Wilson A, Graff-Guerrero A. Ventral striatum binding of a dopamine D2/3 receptor agonist but not antagonist predicts normal body mass index. Biol Psychiatry. 2015;77(2):196-202.

95. Thomsen G, Ziebell M, Jensen PS, da Cuhna-Bang S, Knudsen GM, Pinborg LH. No correlation between body mass index and striatal dopamine transporter availability in healthy volunteers using SPECT and [123I]PE2I. Obesity. 2013;21:1803-6.

96. Adams WK, Sussman JL, Kaur S, D'souza AM, Kieffer TJ, Winstanley CA. Long-term, calorie-restricted intake of a high-fat diet in rats reduces impulse control and ventral striatal D2 receptor signalling - two markers of addiction vulnerability. Eur J Neurosci. 2015;42:3095-104.

97. Zhang C, Wei N-L, Wang Y, Wang X, Zhang J-G, Zhang K. Deep brain stimulation of the nucleus accumbens shell induces antiobesity effects in obese rats with alteration of dopamine neurotransmission. Neurosci Lett. 2015;589:1-6.

98. Jones KT, Woods C, Zhen J, Antonio T, Carr KD, Reith MEA. Effects of diet and insulin on dopamine transporter activity and expression in rat caudate-putamen, nucleus accumbens, and midbrain. J Neurochem. 2017;140:728-40.

99. Barry RL, Byun NE, Williams JM, Siuta MA, Tantawy MN, Speed NK, et al. Brief exposure to obesogenic diet disrupts brain dopamine networks. PLoS One. 2018;13:e0191299.

100. Rospond B, Sadakierska-Chudy A, Kazek G, Krośniak M, Bystrowska B, Filip M. Assessment of metabolic and hormonal profiles and striatal dopamine D2 receptor expression following continuous or scheduled high-fat or high-sucrose diet in rats. Pharmacol Rep. 2018.

101. Hryhorczuk C, Florea M, Rodaros D, Poirier I, Daneault C, Des Rosiers C, et al. Dampened mesolimbic dopamine function and signaling by saturated but not monounsaturated dietary lipids. Neuropsychopharmacology. 2016;41:811.

102. Ducrocq F, Hyde A, Fanet H, Oummadi A, Walle R, De SmedtPeyrusse V, et al. Decrease in operant responding under obesogenic diet exposure is not related to deficits in incentive or hedonic processes. Obesity. Wiley Online Library. 2019;27:25563.

103. Labouesse MA, Sartori AM, Weinmann O, Simpson EH, Kellendonk C, Weber-Stadlbauer U. Striatal dopamine 2 receptor upregulation during development predisposes to diet-induced obesity by reducing energy output in mice. Proc Natl Acad Sci. 2018;115:10493-LP - 10498. 
104. Hakim JD, Keay KA. Prolonged ad libitum access to lowconcentration sucrose changes the neurochemistry of the nucleus accumbens in male Sprague-Dawley rats. Physiol Behav. Elsevier. 2019;201:95-103.

105. Patel JC, Stouffer MA, Mancini M, Nicholson C, Carr KD, Rice ME. Interactions between insulin and diet on striatal dopamine uptake kinetics in rodent brain slices. Eur J Neurosci. 2019;49: 794-804.

106. Robinson MJF, Burghardt PR, Patterson CM, Nobile CW, Akil H, Watson SJ, et al. Individual differences in cue-induced motivation and striatal systems in rats susceptible to diet-induced obesity. Neuropsychopharmacology. 2015;40:2113-23.

107. Sharpe MJ, Batchelor HM, Mueller LE, Chang CY, Maes EJP, Niv Y, et al. Dopamine transients delivered in learning contexts do not act as model-free prediction errors. bioRxiv. 2019;574541.

108. Li Y, South T, Han M, Chen J, Wang R, Huang X-F. High-fat diet decreases tyrosine hydroxylase mRNA expression irrespective of obesity susceptibility in mice. Brain Res. 2009;1268:181-9.

109. Slomp M, Belegri E, Blancas-Velazquez AS, Diepenbroek C, Eggels L, Gumbs MCR, et al. Stressing the importance of choice: validity of a preclinical free-choice high-caloric diet paradigm to model behavioural, physiological and molecular adaptations during human diet-induced obesity and metabolic dysfunction. J Neuroendocrinol. John Wiley \& Sons, Ltd (10.1111). 2019;0: e12718.

110. Berland C, Cansell C, Hnasko TS, Magnan C, Luquet S. Dietary triglycerides as signaling molecules that influence reward and motivation. Curr Opin Behav Sci. 2016;9:126-35.

111. Cansell C, Luquet S. Triglyceride sensing in the reward circuitry: a new insight in feeding behaviour regulation. Biochimie. 2016;120: $75-80$.

112. Berthoud H-R, Münzberg H, Morrison CD. Blaming the brain for obesity: integration of hedonic and homeostatic mechanisms. Gastroenterology. 2017;152:1728-38.

113. Wensveen FM, Valentić S, Šestan M, Turk Wensveen T, Polić B. The "Big Bang" in obese fat: events initiating obesity-induced adipose tissue inflammation. Eur J Immunol. 2015;45:2446-56.

114. Lee M-J, Wang Y, Ricci MR, Sullivan S, Russell CD, Fried SK. Acute and chronic regulation of leptin synthesis, storage, and secretion by insulin and dexamethasone in human adipose tissue. Am J Physiol Endocrinol Metab. 2007;292:E858-64.

115. Ramos-Lobo AM, Donato J. The role of leptin in health and disease. Temp Multidiscip Biomed J. 2017;4:258-91.

116. Dunn JP, Kessler RM, Feurer ID, Volkow ND, Patterson BW, Ansari MS, et al. Relationship of dopamine type 2 receptor binding potential with fasting neuroendocrine hormones and insulin sensitivity in human obesity. Diabetes Care. 2012;35:1105-11.

117. Edwards A, Abizaid A. Clarifying the ghrelin system's ability to regulate feeding behaviours despite enigmatic spatial separation of the GHSR and its endogenous ligand. Int J Mol Sci. 2017;18: E859.

118. Le Roux CW, Patterson M, Vincent RP, Hunt C, Ghatei MA, Bloom SR. Postprandial plasma ghrelin is suppressed proportional to meal calorie content in normal-weight but not obese subjects. $\mathrm{J}$ Clin Endocrinol Metab. 2005;90:1068-71.

119. Hernandez D, Mehta N, Geliebter A. Meal-related acyl and desacyl ghrelin and other appetite-related hormones in people with obesity and binge eating. Obesity. 2019;27:629-35.

120. Dardzińska JA, Małgorzewicz S, Kaska Ł, Proczko M, Stefaniak T, Stankiewicz M, et al. Fasting and postprandial acyl and desacyl ghrelin levels in obese and non-obese subjects. Endokrynol Pol. 2014;65:377-81.

121. McLaughlin T, Abbasi F, Lamendola C, Frayo RS, Cummings DE. Plasma ghrelin concentrations are decreased in insulinresistant obese adults relative to equally obese insulin-sensitive controls. J Clin Endocrinol Metab. 2004;89:1630-5.
122. Julliard A-K, Al Koborssy D, Fadool DA, Palouzier-Paulignan B. Nutrient sensing: another chemosensitivity of the olfactory system. Front Physiol. 2017;8:468.

123. Figlewicz DP. Expression of receptors for insulin and leptin in the ventral tegmental area/substantia nigra (VTA/SN) of the rat: historical perspective. Brain Res. 2016;1645:68-70.

124. Ferrini F, Salio C, Lossi L, Merighi A. Ghrelin in central neurons. Curr Neuropharmacol. 2009;7:37-49.

125. Naef L, Seabrook L, Hsiao J, Li C, Borgland SL. Insulin in the ventral tegmental area reduces cocaine-evoked dopamine in the nucleus accumbens in vivo. Eur J Neurosci.; 2018

126. Stouffer MA, Woods CA, Patel JC, Lee CR, Witkovsky P, Bao L, et al. Insulin enhances striatal dopamine release by activating cholinergic interneurons and thereby signals reward. Nat Commun. 2015;6:8543.

127. Kullmann S, Heni M, Fritsche A, Preissl H. Insulin action in the human brain: evidence from neuroimaging studies. J Neuroendocrinol. 2015;27:419-23.

128. van der Plasse G, van Zessen R, Luijendijk MCM, Erkan H, Stuber GD, Ramakers GMJ, et al. Modulation of cue-induced firing of ventral tegmental area dopamine neurons by leptin and ghrelin. Int J Obes. 2015;39:1742-9.

129. Liu J-J, Bello NT, Pang ZP. Presynaptic regulation of leptin in a defined lateral hypothalamus-ventral tegmental area neurocircuitry depends on energy state. J Neurosci. 2017;37: 11854-66 In this diet-intervention study in rats, leptin regulation was investigated in both hypothalamus and the dopaminergic VTA and could be related to behavioral performance on a conditioned place preference test.

130. Galic S, Oakhill JS, Steinberg GR. Adipose tissue as an endocrine organ. Mol Cell Endocrinol. 2010;316:129-39.

131. Smitka $K$, Marešová $D$. Adipose tissue as an endocrine organ: an update on pro-inflammatory and anti-inflammatory microenvironment. Prague Med Rep. 2015;116:87-111.

132. Treadway MT, Admon R, Arulpragasam AR, Mehta M, Douglas S, Vitaliano G, et al. Association between interleukin- 6 and striatal prediction-error signals following acute stress in healthy female participants. Biol Psychiatry. 2017;82:570-7.

133. Harrison NA, Voon V, Cercignani M, Cooper EA, Pessiglione M, Critchley HD. A neurocomputational account of how inflammation enhances sensitivity to punishments versus rewards. Biol Psychiatry. 2016;80:73-81.

134. Petrulli JR, Kalish B, Nabulsi NB, Huang Y, Hannestad J, Morris ED. Systemic inflammation enhances stimulant-induced striatal dopamine elevation. Transl Psychiatry. 2017;7:e1076.

135. Felger JC, Treadway MT. Inflammation effects on motivation and motor activity: role of dopamine. Neuropsychopharmacol Am Coll Neuropsychopharmacol. 2016;42:216.

136. Dixit VD, Schaffer EM, Pyle RS, Collins G, Sakthivel SK, Palaniappan R, et al. Ghrelin inhibits leptin- and activationinduced proinflammatory cytokine expression by human monocytes and T cells. J Clin Invest. 2004;114:57-66.

137. Wang X, van Villar A, Tiu A, Upadhyay KK, Cuevas S. Dopamine D2 receptor upregulates leptin and IL-6 in adipocytes. J Lipid Res. 2018;59:607-14.

138. Ezrokhi M, Luo S, Trubitsyna Y, Cincotta AH. Neuroendocrine and metabolic components of dopamine agonist amelioration of metabolic syndrome in SHR rats. Diabetol Metab Syndr. 2014;6: 104.

139. Alexander GE, DeLong MR, Strick PL. Parallel organization of functionally segregated circuits linking basal ganglia and cortex. Annu Rev Neurosci. 1986;9:357-81.

140. Haber SN, Knutson B. The reward circuit: linking primate anatomy and human imaging. Neuropsychopharmacology. 2010;35:426. 
141. Draganski B, Kherif F, Klöppel S, Cook PA, Alexander DC, Parker GJM, et al. Evidence for segregated and integrative connectivity patterns in the human basal ganglia. J Neurosci. 2008;28: $7143-52$.

142. Aarts E, van Holstein M, Cools R. Striatal dopamine and the interface between motivation and cognition. Front Psychol. $2011 ; 2$.

143. Choi EY, Ding S-L, Haber SN. Combinatorial inputs to the ventral striatum from the temporal cortex, frontal cortex, and amygdala: implications for segmenting the striatum. Eneuro. 2017;4: ENEURO.0392-17.2017.

144. Lippert RN, Cremer AL, Edwin Thanarajah S, Korn C, JahansPrice T, Burgeno LM, et al. Time-dependent assessment of stimulus-evoked regional dopamine release. Nat Commun. 2019; $10: 336$

145. Thanarajah SE, Backes H, DiFeliceantonio AG, Albus K, Cremer AL, Hanssen R, et al. Food intake recruits orosensory and postingestive dopaminergic circuits to affect eating desire in humans. Cell Metab. 2019;29:695-706 This is the first study that could show dopamine responses in striatal and frontal regions in response to food intake in humans using their newly developed PET-method.

146. Laubach M, Amarante LM, Swanson K, White SR. What, if anything, is rodent prefrontal cortex? eNeuro Soc Neurosci. 2018;5: ENEURO.0315-18.

147. Stroebele N, De Castro JM. Effect of ambience on food intake and food choice. Nutrition. 2004;20:821-38.

148. Gaillet-Torrent M, Sulmont-Rossé C, Issanchou S, Chabanet C, Chambaron S. Impact of a non-attentively perceived odour on subsequent food choices. Appetite. 2014;76:17-22.

149. Overberg J, Hummel T, Krude H, Wiegand S. Differences in taste sensitivity between obese and non-obese children and adolescents. Arch Dis Child. 2012;97:1048-52.

150. Proserpio C, Laureati M, Invitti C, Pagliarini E. Reduced taste responsiveness and increased food neophobia characterize obese adults. Food Qual Prefer. 2018;63:73-9.

151. Martinez-Cordero E, Malacara-Hernandez JM, Martinez-Cordero C. Taste perception in normal and overweight Mexican adults. Appetite. 2015;89:192-5.

152. Stafford LD, Whittle A. Obese individuals have higher preference and sensitivity to odor of chocolate. Chem Senses. 2015;40:27984.

153. Pignatelli A, Belluzzi O. Dopaminergic neurones in the main olfactory bulb: an overview from an electrophysiological perspective. Front Neuroanat. 2017;11:7.

154. Ilkiw JL, Kmita LC, Targa ADS, Noseda ACD, Rodrigues LS, Dorieux FWC, et al. Dopaminergic lesion in the olfactory bulb restores olfaction and induces depressive-like behaviors in a 6OHDA model of Parkinson's disease. Mol Neurobiol. 2019;56: 1082-95.

155. Boswell RG, Kober H. Food cue reactivity and craving predict eating and weight gain: a meta-analytic review. Obes Rev. 2016;17:159-77.

156. van den Akker K, Stewart K, Antoniou EE, Palmberg A, Jansen A. Food cue reactivity, obesity, and impulsivity: are they associated? Curr Addict Reports. 2014;1:301-8.

157. Michaud A, Vainik U, Garcia-Garcia I, Dagher A. Overlapping neural endophenotypes in addiction and obesity. Front Endocrinol (Lausanne) Front Media S.A. 2017;8:127.

158. Giel EK, Teufel M, Junne F, Zipfel S, Schag K. Food-related impulsivity in obesity and binge eating disorder - a systematic update of the evidence. Nutr. 2017:1170.

159. Loxton NJ. The role of reward sensitivity and impulsivity in overeating and food addiction. Curr Addict Reports. 2018;5:212-22.

160. Sescousse G, Caldú X, Segura B, Dreher J-C. Processing of primary and secondary rewards: a quantitative meta-analysis and review of human functional neuroimaging studies. Neurosci Biobehav Rev. 2013;37:681-96.

161. Yousuf M, Heldmann M, Göttlich M, Münte TF, Doñamayor N. Neural processing of food and monetary rewards is modulated by metabolic state. Brain Imaging Behav. 2018;12:1379-92.

162. Luijten M, Schellekens AF, Kühn S, Machielse MJ, Sescousse G. Disruption of reward processing in addiction: an image-based meta-analysis of functional magnetic resonance imaging studies. JAMA Psychiatry. 2017;74:387-98.

163. Hendrikse JJ, Cachia RL, Kothe EJ, McPhie S, Skouteris H, Hayden MJ. Attentional biases for food cues in overweight and individuals with obesity: a systematic review of the literature. Obes Rev. Wiley Online Library. 2015;16:424-32.

164. Roefs A, Franssen S, Jansen A. The dynamic nature of food reward processing in the brain. Curr Opin Clin Nutr Metab Care LWW. 2018;21:444-8 Interesting review that provides a compelling explanation for the inconsistent results with regard to food attentional bias and reward processing in obesity and eating disorders and encourages researchers to take into account the dynamic nature of these processes.

165. Lopez RB, Hofmann W, Wagner DD, Kelley WM, Heatherton TF. Neural predictors of giving in to temptation in daily life. Psychol Sci. 2014;25:1337-44.

166. Mathar D, Horstmann A, Pleger B, Villringer A, Neumann J. Is it worth the effort? Novel insights into obesity-associated alterations in cost-benefit decision-making. Front Behav Neurosci. 2016;9: 360.

167. Amlung M, Petker T, Jackson J, Balodis I, MacKillop J. Steep discounting of delayed monetary and food rewards in obesity: a meta-analysis. Psychol Med. 2016;46:2423-34.

168. Barlow P, Reeves A, McKee M, Galea G, Stuckler D. Unhealthy diets, obesity and time discounting: a systematic literature review and network analysis. Obes Rev. John Wiley \& Sons, Ltd (10.1111). 2016;17:810-9.

169. McClelland J, Dalton B, Kekic M, Bartholdy S, Campbell IC, Schmidt U. A systematic review of temporal discounting in eating disorders and obesity: behavioural and neuroimaging findings. Neurosci Biobehav Rev. 2016;71:506-28.

170. Tang J, Chrzanowski-Smith OJ, Hutchinson G, Kee F, Hunter RF. Relationship between monetary delay discounting and obesity: a systematic review and meta-regression. Int J Obes. 2018;43:113546.

171. Correa M, Carlson BB, Wisniecki A, Salamone JD. Nucleus accumbens dopamine and work requirements on interval schedules. Behav Brain Res. 2002;137:179-87.

172. Salamone JD, Correa M, Farrar A, Mingote SM. Effort-related functions of nucleus accumbens dopamine and associated forebrain circuits. Psychopharmacology. 2007;191:461-82.

173. Draper A, Koch RM, van der Meer JWM, AJ Apps M, Pickkers P, Husain M, et al. Effort but not reward sensitivity is altered by acute sickness induced by experimental endotoxemia in humans. Neuropsychopharmacology. 2017;43:1107.

174. Stein JS, Sze YY, Athamneh L, Koffarnus MN, Epstein LH, Bickel WK. Think fast: rapid assessment of the effects of episodic future thinking on delay discounting in overweight/obese participants. J Behav Med. 2017;40:832-8.

175. Sze YY, Stein JS, Bickel WK, Paluch RA, Epstein LH. Bleak present, bright future: online episodic future thinking, scarcity, delay discounting, and food demand. Clin Psychol Sci :A J Assoc Psychol Sci. 2017;5:683-97.

176. Dassen FCM, Jansen A, Nederkoorn C, Houben K. Focus on the future: episodic future thinking reduces discount rate and snacking. Appetite. 2016;96:327-32.

177. Daniel TO, Stanton CM, Epstein LH. The future is now: reducing impulsivity and energy intake using episodic future thinking. Psychol Sci. 2013;24:2339-42. 
178. Daniel TO, Stanton CM, Epstein LH. The future is now: comparing the effect of episodic future thinking on impulsivity in lean and obese individuals. Appetite. 2013;71:120-5.

179. Daniel TO, Said M, Stanton CM, Epstein LH. Episodic future thinking reduces delay discounting and energy intake in children. Eat Behav. 2015;18:20-4.

180. Peters J, Büchel C. Episodic future thinking reduces reward delay discounting through an enhancement of prefrontal-mediotemporal interactions. Neuron. 2010;66:138-48.

181. Schacter DL, Benoit RG, Szpunar KK. Episodic future thinking: mechanisms and functions. Curr Opin Behav Sci. 2017;17:41-50.

182. Baek K, Morris LS, Kundu P, Voon V. Disrupted resting-state brain network properties in obesity: decreased global and putaminal cortico-striatal network efficiency. Psychol Med. 2017;47:585-96.

183. Lavagnino L, Arnone D, Cao B, Soares JC, Selvaraj S. Inhibitory control in obesity and binge eating disorder: a systematic review and meta-analysis of neurocognitive and neuroimaging studies. Neurosci Biobehav Rev. 2016;68:714-26.

184. Veling H, Aarts H, Stroebe W. Using stop signals to reduce impulsive choices for palatable unhealthy foods. Br J Health Psychol. Wiley Online Library. 2013;18:354-68.

185. Veling H, Aarts H, Stroebe W. Stop signals decrease choices for palatable foods through decreased food evaluation. Front Psychol Front. 2013;4:875.

186. Stice E, Lawrence NS, Kemps E, Veling H. Training motor responses to food: a novel treatment for obesity targeting implicit processes. Clin Psychol Rev Elsevier. 2016;49:16-27.
187. Veling H, Lawrence NS, Chen Z, van Koningsbruggen GM, Holland RW. What is trained during food go/no-go training? A review focusing on mechanisms and a research agenda. Curr Addict Reports. 2017;4:35-41.

188. Mehl N, Morys F, Villringer A, Horstmann A. Unhealthy yet avoidable - how cognitive bias modification alters behavioral and brain responses to food cues in individuals with obesity. Nutr Multidiscip Dig Publ Inst. 2019;11:874.

189. Nam SB, Kim K, Kim BS, Im H-J, Lee SH, Kim S-J, et al. The effect of obesity on the availabilities of dopamine and serotonin transporters. Sci Rep Nat Publ Group. 2018;8:4924.

190. Hesse S, van de Giessen E, Zientek F, Petroff D, Winter K, Dickson JC, et al. Association of central serotonin transporter availability and body mass index in healthy Europeans. Eur Neuropsychopharmacol. Elsevier. 2014;24:1240-7.

191. Koob GF, Volkow ND. Neurocircuitry of addiction. Neuropsychopharmacology Nat Publ Group. 2010;35:217-38.

Publisher's Note Springer Nature remains neutral with regard to jurisdictional claims in published maps and institutional affiliations. 